\title{
The effect of an applied behavior analysis based treatment on the participation of a kindergarten student with Autism Spectrum Disorder in a general education classroom
}

\author{
Brandi Slider \\ West Virginia University
}

Follow this and additional works at: https://researchrepository.wvu.edu/etd

\section{Recommended Citation}

Slider, Brandi, "The effect of an applied behavior analysis based treatment on the participation of a kindergarten student with Autism Spectrum Disorder in a general education classroom" (2009). Graduate Theses, Dissertations, and Problem Reports. 694.

https://researchrepository.wvu.edu/etd/694

This Thesis is protected by copyright and/or related rights. It has been brought to you by the The Research Repository @WVU with permission from the rights-holder(s). You are free to use this Thesis in any way that is permitted by the copyright and related rights legislation that applies to your use. For other uses you must obtain permission from the rights-holder(s) directly, unless additional rights are indicated by a Creative Commons license in the record and/ or on the work itself. This Thesis has been accepted for inclusion in WVU Graduate Theses, Dissertations, and Problem Reports collection by an authorized administrator of The Research Repository @ WVU. For more information, please contact researchrepository@mail.wvu.edu. 
The Effect of an Applied Behavior Analysis Based Treatment on the Participation of a Kindergarten Student with Autism Spectrum Disorder in a General Education Classroom

Brandi Slider

Thesis submitted to the

College of Human Resources and Education

at West Virginia University

in partial fulfillment of the requirements for the degree of

\author{
Master of Arts \\ Educational Psychology \\ Child Development and Family Studies
}

\author{
Daniel E. Hursh, Ph.D., Chair \\ Reagan P. Curtis, Ph.D \\ Barbara G. Warash, Ed.D
}

Department of Technology Learning and Culture

Morgantown, West Virginia

2009 


\begin{abstract}
The Effect of an Applied Behavior Analysis Based Treatment on the Participation of a Kindergarten Student with Autism Spectrum Disorder in a General Education Classroom

Brandi Slider

This project was developed with the intention of helping to integrate a child diagnosed with Autism Spectrum Disorder more fully into a general education classroom. The study was a single case design experiment employing a multiple-baseline design across situations intended to increase appropriate participation and decrease inappropriate participation. The Competent Learner Model was used as a tool to develop observation skills and to identify target behaviors to change for the learner. An Applied Behavior Analysis based token-economy system served as the intervention, utilizing stickers in exchange for preferred activities. The intervention was applied at three intervals across two situations with each application related to an increase in appropriate participation and a decrease in inappropriate participation. The results supported the hypothesis that the intervention would have a positive effect on appropriate participation and a negative effect on inappropriate participation. An increase in trend and mean and a decrease in variability in targeted behaviors supported the intervention effect. This study further supports Applied Behavior Analysis as an effective tool in the classroom and as an aid to help integrate children with an Autism Spectrum Disorder Diagnosis into the general education classroom.
\end{abstract}




\section{Table of Contents}

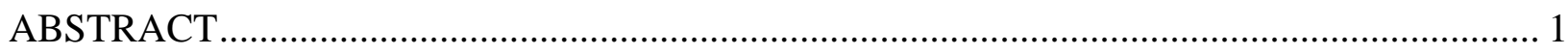

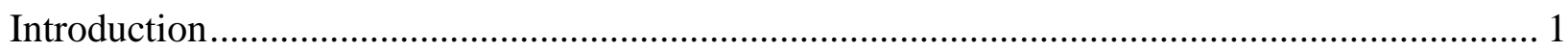

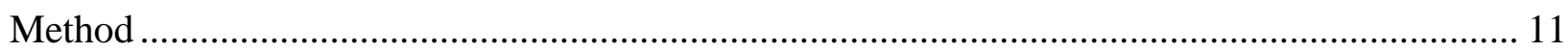

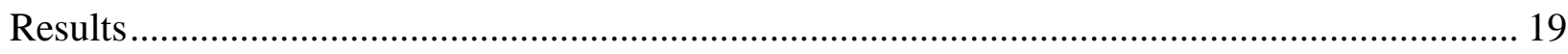

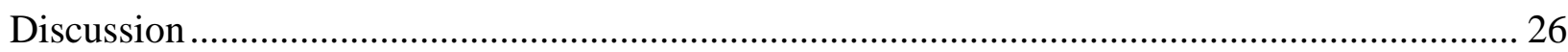

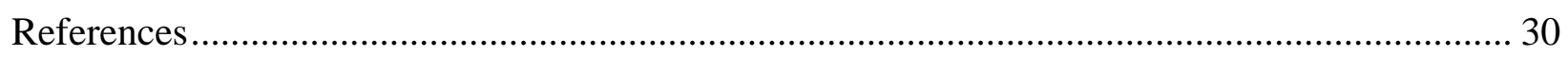

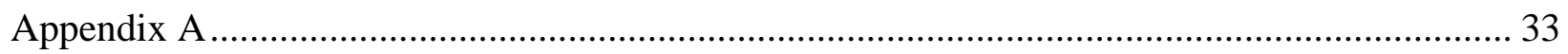

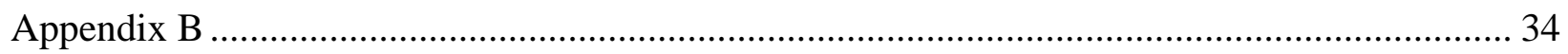

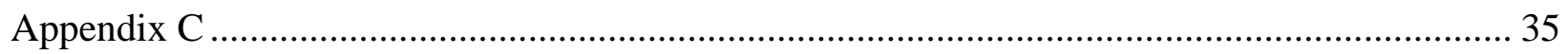




\section{Introduction}

The label of pervasive developmental delays (PDD) is a broad category of afflictions defined by a person having impairments in more than one of the following areas of development: reciprocal social interaction skills, communication skills, or the presence of stereotyped behavior, interests, and activities (DSM-IV, 1994). The degree of impairment and affected developmental areas vary from person to person. Included under the umbrella of PDD are Autism Spectrum Disorder (ASD), Rett's Disorder, Childhood Disintegrative Disorder, Asperger's Disorder, and Pervasive Developmental Disorder-Not Otherwise Specified. PDDs are often accompanied by some degree of Mental Retardation, though this is not always the case. Additionally, a variety of co morbid medical disorders occur with PDD such as chromosomal abnormalities, congenital infections, and structural abnormalities of the central nervous system.

ASD as included under PDD in the Diagnostic and Statistical Manual of Mental Disorders IV (DSM-IV), is described as the "presence of markedly abnormal or impaired development in social interaction and communication and a markedly restricted repertoire of activity and interests" (DSM-IV, p. 66). In addition, 75\% of children diagnosed with ASD have some level of Mental Retardation. Behavioral disorders also frequently accompany a diagnosis of ASD and can include hyperactivity, impulsiveness, aggression, limited span of attention, selfinjury, and temper tantrums in young children. External stimuli can produce abnormal responses in a person with ASD, as well as disturbances in sleep, eating, and mood. In regards to verbal communication, expressive language is higher than language comprehension when compared to typically developing children with whom the two are roughly equal.

Although ASD was only identified as a disorder in 1943, reports of behaviors that are known symptoms of ASD have been noted since the $18^{\text {th }}$ century (Dyck, Piek, Hay, \& Hallmeyer, 2007). A single cause of ASD has not been discovered and scientists believe that both genetics and environmental elements lead to the disorder (National Institute of Neurological Disorders and Stroke, 2008). Multiple genes have been associated with ASD, along with brain irregularities in multiple regions although no specific pattern has emerged in regard to these irregularities. Other suspected causes are atypical serotonin or other neurotransmitter levels in the brain. These brain abnormalities suggest that a potential disruption of brain development during pregnancy may play a role in the development of ASD. Moreover, a familial link has been found with the prevalence of a family who has one child with ASD having an increased risk (1 in 20) of their second child being diagnosed with ASD. This risk is greater than that of the general population, which is currently at 3-6 of every 1,000 children being diagnosed with ASD. In the general population the occurrence of ASD has increased dramatically from 2-5 cases per 10,000 in 1994 to the 3-6 per 1,000 from 2008. Although the true impetus is unknown, potential causes of the increase have been identified as a simple increase in occurrence of the disorder, a broader diagnosis of ASD, improved diagnostic methods, and greater awareness concerning ASD among parents and professionals. Occurring across all racial, ethnic, and socioeconomic groups the disorder is not associated with a particular population; however, males are four times as likely to be affected by autistic disorders as females (Dyck et al., 2007).

Current Research on ASD and Inclusion 
In order to find studies for review purposes, searches were conducted on the ERIC database using the thesaurus tool including queries of autism and inclusion. Additionally, the search was limited to journal articles reporting results of experimental studies or meta-analyses. After probing the abstracts of such investigations for relevancy, references from these works were utilized to locate the remainder of studies through available electronic journals from a university library.

To meet inclusion criteria, studies selected had to have all or a majority of participants coping with ASD. Moreover, the ages of all parties within the projects ranged from 58 months to 12 years, excepting 6 participants who were over the age of 12; thus keeping a preponderance of participants within the elementary school age range in order to remain relevant to the current application. Finally, studies had to be dealing with children who participated in an inclusive classroom setting. Nearly all of the investigations included an intervention that took place in an inclusive classroom setting, and those that did not included a discussion of generalization of the treatment effect to the general education classroom setting.

The experimental methods utilized by the majority of the studies allow for clear inferences regarding the impact of the interventions because the variables were systematically manipulated in controlled settings. Further, all of the meta-analyses analyzed experimentally designed studies supporting the impact of the interventions. The results of the correlational and descriptive studies were consistent with the impact of the interventions experimentally analyzed in the other studies. The review supports numerous treatment methods available and in use for helping children with ASD succeeds in the general education setting. Every application included shared a focus of changing some type of behavior, whether to increase desired behaviors or decrease undesired behaviors. Another commonality between the investigations is the absence of punishment to decrease objectionable actions. The number of demonstrated treatment strategies supports the complexity of ASD and current limited knowledge of how to integrate ASD students into the classroom effectively.

The review of literature is organized by who was most directly involved in the proceedings or intervention delivery of the study with the identified participants. The first study by Ochs, Kremer-Sadlik, Solomon, and Sirota (2001) is a correlational design investigating the involvement of both peers and staff in the integration of the target student. The succeeding three studies employ peers as the main actors in the intervention delivery (Buggey, 2005; Pierce \& Schreibman, 1997; Thiemann \& Goldstein, 2001). Next, three more studies are discussed which employ staff as the main people who are involved in the intervention delivery (Conroy, Asmus, Ladwig, Sellers, \& Valcante, 2004; Eikeseth, Smith, \& Eldeveik, 2002; Polychronis, McDonnell, Johnson, Riesen, \& Jameson, 2004). Finally, three meta-analyses are examined that expand on and support the findings from the previously listed studies (Delano, 2007; Odom, Brown, Frey, Karasu, Smith-Canter, \& Strain, 2003; Levy, Kim, \& Olive, 2006). The studies are arranged as can be viewed in Table 1 below. 


\begin{tabular}{|c|c|c|c|}
\hline Authors & Date & Study Participants & Study Type \\
\hline $\begin{array}{c}\text { Ochs, Kremer-Sadlik, } \\
\text { Solomon, \& Sirota }\end{array}$ & 2001 & Peers and Staff & Correlational \\
\hline Buggey & 2005 & Peers and Staff & Experimental Intervention \\
\hline Thiemann \& Goldstein & 2001 & Peers & Experimental Intervention \\
\hline Pierce \& Schreibman & 1997 & Peers & Experimental Intervention \\
\hline $\begin{array}{c}\text { Conroy, Asmus, Ladwig, } \\
\text { Sellers, \& Valcante }\end{array}$ & 2004 & Staff & Correlational \\
\hline Eikeseth, Smith, \& Eldevik & 2002 & Staff & Experimental Intervention \\
\hline $\begin{array}{c}\text { Polychronis, McDonnell, } \\
\text { Johnson, Riesen, \& Jameson }\end{array}$ & 2004 & Staff & Experimental Intervention \\
\hline Delano & 2007 & N/A & Meta-Analysis \\
\hline $\begin{array}{c}\text { Odom, Brown, Frey, Karasu, } \\
\text { Smith-Canter, \& Strain }\end{array}$ & 2003 & N/A & Meta-Analysis \\
\hline Levy, Kim, \& Olive & 2006 & N/A & Metals \\
\hline
\end{tabular}

Table 1. The arrangement of studies in the review of literature.

The first study (Ochs et al., 2001) presents information about a tool that could aid in classroom integration for students with a diagnosis of ASD. It is a device that can potentially be used as a classroom procedure to help staff and peers in the classroom be accepting and understanding of the focus child. Disclosure of the ASD diagnosis was not meant to provide an excuse for children, but rather to augment understanding of atypical or inappropriate behaviors of the student that could potentially isolate them from beneficial social interactions. In this investigation, the degree of disclosure to staff and classmates about a student's ASD was correlated with the amount of positive inclusion the child experienced. Findings revealed that the more open the classroom discussion of the child's diagnosis, the more positive inclusion they received both from classmates and staff. Further, when family and staff teamed together to teach peers about their classmate's behaviors and diagnosis, peers had more positive interactions with the student with ASD and responded in a more positive manner to negative or odd behaviors by the student. Even though all ASD students did experience some exclusion from classroom activities, this was less prevalent in classrooms where children and teachers were aware of the child's diagnosis. Although this was a correlational study and cause and effect cannot be determined, the association between disclosure and a positive inclusive environment are important and warrant further study. Findings can and may encourage parents, teachers, and children to be open-minded about disclosure and its potential benefits for everyone in an inclusive classroom.

A work by Buggey (2005) executed three single-case design studies using video modeling to change behavior involving both peers and staff in the process. The first design had two students, prior to class, watch themselves on video exhibiting unsolicited verbalizations addressed to peers and staff. Results from this intervention showed a substantial increase for both students in social initiations. In the second experiment Buggey again used self-modeling of two students to decrease the rate and duration of tantrums in the classroom. Each student, along with peers and staff, modeled appropriate behaviors following situations that typically resulted in tantrums. Both students displayed dramatic decreases in tantrum rate and duration, with neither 
showing any incidence of tantrums during follow up. With three other students in a different intervention study Buggey attempted to increase spontaneous conversation with peers and staff, utilizing videos of the two target children and a peer and/or teacher engaging in conversation. The students then individually watched their respective videos daily before class with results indicating a substantial increase in both students' verbalizations with peers and teachers.

The next studies utilize only peers as purveyors of the interventions. Thiemann and Goldstein (2001) used recorded videos of students with ASD and their classmates in appropriate classroom situations to help teach social skills to the target children. This particular design utilized pictures and written cues in addition to video instruction to teach social skills. The study briefly touched on decreasing inappropriate vocalizations and included measurements on the rates of inappropriate topic change, unintelligible utterances, no response, and "other" including animal noises, echolalia, etc. Measurements indicated that these behaviors decreased over the course of time; however they were not specifically targeted as skills to modify. Conversely, four specific areas were targeted to increase including securing attention, initiating comments, coming up with appropriate responses, and contingent responses to peers. Peers and identified students read social stories related to desired actions, discussed picture cards of the desired actions, and then practiced role playing appropriate social exchanges. After these steps occurred, children then watched recordings of the proceedings and gave yes or no answers on whether they had completed the task. Results showed increased specific social skills for all five identified children, with effects replicated across the four chosen social behaviors. However, after a maintenance period some of the students did return to baseline behaviors for some, but not all of the targeted responses after removal of prompts and visual cues. This led researchers to believe that some children may require booster sessions or a longer training time to fully acquire the desired skills. Nevertheless, the results were promising due to the initial effects and need more research for continued support.

Another study by Pierce and Schreibman (1997) again used only peers as a resource to increase positive social interactions. Pivotal Response Training was used in this study to teach students to augment social interactions, with a focus on duration of exchange and initiation of play and spontaneous conversation. Increased rates of the desired social behaviors were exhibited after students with ASD and peers practiced staged interactions in a resource room. Results were observed in the resource and inclusive classrooms with ASD students showing a generalization of skills in the general education class. These studies are helpful as they lend support to the role visual aids can play in the modification of desirable behaviors for students with ASD. What is more, all of these studies show that in addition to staff and specialists, peers can also play an important role in the integration of children with ASD in the classroom.

The next three studies review how adults interacting and intervening with the target children are associated with changes in students' behavior. Conroy et al. (2004) analyzed the effect of adult proximity on increasing on task academic behavior and the following of directives. A positive link was exhibited between the presence of adult proximity, an adult within $3 \mathrm{ft}$ of the child, and an increase in on task academic behavior. However, in regard to adult directives, adult proximity had inconsistent findings. For three of the six students in the study, proximity increased the likelihood of disruptive behavior after a directive; while for one student adult proximity decreased the likelihood of disruptive behavior. The other two students showed no specific pattern of behavior when given a directive within proximity to an adult. This led to the assumption that adult proximity and following directions may be dependent upon the 
individual. It is suggested, as has been found in other studies, that the discriminative stimuli of an adult being near may signal different outcomes for different children. Importantly, this supports the postulation that the relationship between discriminative stimuli and problem behaviors must be ascertained, as well as the consequences that sustain the actions.

Another study employing adults exclusively as interventionists was performed by Eikeseth et al. (2002) utilizing two different treatment interventions to compare increases in cognitive skills. The first treatment was intensive behavioral therapy based on ABA, and the other treatment was an eclectic treatment containing a combination of intervention variables from ABA, Project TEACCH, sensory-motor therapies, and methods from therapists' own personal experiences. These treatment methods were compared over a one-year time period for 19 children with a diagnosis of ASD in an inclusive kindergarten setting. Testing was initially done to ensure treatment groups were not different from one another across variables with measurements including such well-known instruments as the Wechsler Preschool and Primary Scale of Intelligence-Revised, Bayley Scales of Infant Development-Revised, Merrill-Palmer Scale of Mental tests, Reynell Developmental Language Scales, and the Vineland Adaptive Behavior Scales. Findings indicated that both groups showed increases on all tests, but students in the intensive behavioral therapy group had higher scores across all but one of the surveyed areas, socialization as scored on the Vineland Scales; however, none of the differences between groups were statistically significant. It is surmised that multiple factors played a role in the results such as similar treatment goals for both groups, relatively high average intelligence for children with ASD at 64, and finally, that the eclectic treatment group did contain more intensive behavioral therapy techniques than did eclectic groups in past comparison studies. Additionally, the sample size was limited to 19 children. Despite these drawbacks, the positive increases in cognitive functioning due to these treatments do give credence to the ABA treatment method.

The final study involving solely adults focused on academic achievement and was a comparison of the effectiveness of different schedules of embedded instruction on specific academic skills as identified in each student's individual education plan (Polychronis et al., 2004). The work compared two schedules of instruction across four students with ASD by testing variables of the same skill with each schedule. Embedded instruction is similar to traditional teaching methods in that the teacher controls delivery of instruction and the instruction is designed to support a student acquiring a skill. Differing from traditional methods is the technique of delivering the instruction across multiple activities, rather than during a discrete time period. Both schedules of embedded instruction, 30 and 120 min time intervals, were found to be adequate in teaching the skills; however the skills taught in 30 min intervals were acquired quicker by the learners, though not significantly quicker. The benefits of this specific study show that teachers were able to implement the embedded instruction in an entirely inclusive setting and that those skills targeted did generalize to other materials and also to other situations than those originally intended. Limitations to this study include a small sample size and the specificity of the task learned.

Next, three meta-analyses have been included to support and add to findings from previous studies. A review was done by Delano (2007) surveying the effectiveness of different types of video modeling and included 19 experimental studies employing one or more of the following video usages to gain increases in target behaviors: models of others, model of self, comparison of in vivo or video intervention, and comparison of self and other as model types. The review measured the value of each study in regards to interobserver agreement rates, fidelity 
measures, and validity assessment. Overall, the findings suggest that video modeling was related to positive gains in social-communicative skills, functional skills, perspective taking skills, and in the reduction of problem behavior. Some findings were prevalent but not strong, including that watching the self may be a more effective model than observing others; the intensity of video modeling may be lacking and require other treatment supports; and finally, that individual traits may affect the effectiveness of the method. Generalization was assessed in all but two of the studies and showed positive results. In all, the review did reveal some limitations to the studies including most having small sample sizes, a lack of fidelity measures in regard to video creation, a lack of research on whether skills were meaningful to participants or just limited to aspects of ASD in general, and a lack of comparison of effectiveness to traditional ASD interventions. Despite these short falls, video modeling was shown to be effective in home, school, and community settings and also that it did lead to behavioral generalization. These two important factors show the versatility and usability of video modeling as a helpful tool in classroom management and instruction.

Another meta-analysis completed by Odom et al. (2003) synthesized data regarding evidence-based practices for children with ASD. Treatment types were coded into nine different categories: adult-directed teaching strategies, differential reinforcement, peer-mediated interventions, visual supports, positive behavioral support, self monitoring, video modeling, modification of task characteristics, and family involvement. Thirty-seven studies were analyzed that met inclusion criteria of being published in a peer-reviewed journal, utilizing a singlesubject design that illustrated a causal relationship between the independent and dependent variables, half of participants being diagnosed as having ASD or Pervasive Developmental Disorder-Not Otherwise Specified, and finally, a minimum of $50 \%$ of the children had to be 6 years old or younger. The authors ranked the practices into groups, with adult prompting and differential reinforcement of behavior at the top as "well established." Following as the next most effective was the assemblage of "emerging and effective" made up of peer-mediated intervention, visual supports, self-monitoring and evaluation, and family involvement. The final ranked group, titled "probably efficacious," consisted of positive behavioral support, task modification, and video modeling. Some limitations were noted, including a limited number of studies that measured treatment fidelity. Both generalization and maintenance effects were reported less frequently than would be desirable. A final flaw showed limited social validity concerning the studies. Despite these drawbacks, the examination manifested rankings of types of interventions and demonstrated the degree of meticulous control of experimental evidence single-subject designs can exert.

The final included meta-analysis was conducted as a post-hoc analysis of 24 studies focusing on interventions for juvenile children with ASD (Levy, Kim, \& Olive, 2006). Works included were adherent to the following guidelines: experimental intervention occurred, design was either treatment/comparison or single-group, a minimum of 2/3 of the children were ages 38 years, at least $50 \%$ of those included in the study had an ASD diagnosis, and the publication had to have been produced between 1975 and 2001. The analysis measured the effect sizes of parent involvement, intensive behavioral intervention, multi-component intervention, language or speech therapy, setting, and “other" interventions. Parent involvement was measured in six studies and was associated with positive outcomes for all treated. Intensive behavioral treatment included four studies with affirmative outcomes reported by all four. Again, both multicomponent early intervention and language/speech therapies produced positive gain. Studies concerning settings scrutinized the effects of typically developing children on social and 
behavioral results of students with ASD and had positive outcomes in all cases. Treatments grouped in the "other interventions" category were touch therapy, intensive early behavioral intervention, computer program vocabulary training, and imitative interactions with all showing positive gains in their respective domains. General findings showed that an increased duration of intervention was associated with positive outcomes, and also that the early pace of learning was related to the succeeding acquisition of skills. Yet again, in support of previous findings, the presence of typically developing children was related to an increase in positive social outcomes and a decrease in negative autistic behaviors. Four central facets of intervention showed consistently positive achievements across perspectives: parental involvement, intensive behavioral therapy, multi-component interventions, and duration of intervention. Limitations of the work are dated studies that could have more recent findings; the small number of studies included led to a small sample size, a focus solely on group designs, and a limited age range of participants. With these limitations, this study adds to the diversity of the research collected and supports the current work.

The current study adds to the literature a potential new tool to be used in the development of behavioral interventions in the general education classroom. Like many of the studies included the present study uses an ABA tool to manipulate behavior, however the development of the intervention came about by a unique tool the Competent Learner Model (CLM). The success of this experiment lends to the effectiveness of the CLM as a means to develop behavioral interventions for the classroom and this can be studied more directly as a development tool in the future.

\section{Current Trends in Education}

Educational achievement trends being unacceptably low in the United States have led to the passage of the No Child Left Behind Act in 2001 (Yell, Drasgow, \& Lowrey, 2005). The act has been controversial, as it has held school districts, teachers, and school administrators responsible for students' immediate academic achievement. Additionally, it requires educators to use scientifically proven methods for education, achieve high academic standards, provide a safe environment, teach English proficiently to English language learners, and have a $100 \%$ high school graduation rate. Focusing on scientifically supported education methods is imperative to successful education; however making a mandate does not provide the necessary means to achieve a goal. The goals of the act are lofty and important; however, No Child Left Behind has created a system in which schools are not given the means to implement the required changes.

Another concurrent legal move adding to the educators' load is amendments made to the Individuals with Disabilities Education Act. These new laws now require that a child who exhibits behaviors that interfere with their own or classmates' learning have an individualized education plan. Furthermore, the individualized education plan must offer positive behavioral support and requires that staff conduct a functional behavioral assessment and implement a behavioral intervention for the child (Sugai et al., 2000). As with No Child Left Behind, this law has a desirable outcome, but has increased an already heavy teacher workload.

Another issue at the forefront of education in recent years has been inclusion, with a focus on integrating children with disabilities into the general education classroom as fully as possible. Inclusion is based on the concept that when a child is included in a regular rather than special education setting they are exposed to benefits that would otherwise be denied; such as higher teacher expectations, more learning opportunities, positive peer-modeled behavior, and 
increased self-esteem (Mesibov \& Shea, 1996). In the regular education classroom it is expected that children with disabilities are able to participate and can succeed with appropriate support services.

Another hurdle facing school systems is a lack of use of evidence based educational methods, which has left the education community with a dearth of effective teaching tools (Binder \& Watkins, 1990). Teachers have utilized instructional methods that have not been through sound experimental testing to prove whether or not they are effective, and so have had limited success with students who have some type of learning disability. One surmised cause of reliance on unproven teaching methods is an insistence of depending upon grades as markers of educational success. Rigorously tested teaching methods and models have been in existence for decades, but there has been much difficulty disseminating these practices because they do not fit into the current, traditional grading system and are deemed too complicated to be feasible.

\section{The Competent Learner Model}

As a response to these ills, the CLM has been developed as a tool for educators in an effort to aid in instructional delivery in order to increase the educational success of children affected by learning impairments (Tucci, Hursh, Laitinen, \& Lambe, 2005). The CLM is based on tenets of Applied Behavior Analysis (ABA), Precision Teaching (PT), and Direct Instruction (DI) and is used to effect positive change in a learner's abilities. A unique and important aspect of the CLM involves not the teaching of specific skills, but rather giving a student the tools necessary to become a competent learner. Proficiency is achieved through mastery of seven competency areas called the Competent Learner Repertoires: observing, listening, talking, problem solving, participating, reading, and writing. Through mastery of these precise areas, it is premised that a student should have the means to become a competent learner and then generalize this process of learning to diverse settings (Tucci, 2006). The CLM approach envisions learning chiefly as an outcome of individualized instruction across learning milieus.

In addition to providing these learner tools, the CLM training guides teachers in how to tailor educational experiences to each student. Through the teachers' course of study, educators are instructed in how to effectively observe the antecedents and consequences that maintain behaviors, develop and implement behavioral modifications to aid student learning, and how to adjust these behavioral plans in reply to student responses. Teachers are paired with a CLM coach for the duration of their coursework to help prepare them to use the CLM in the classroom. Ultimately, the teachers are given tools that allow them to effectively arrange the environment to help their students become more competent learners.

In more detail, the CLM course of study for educators consists of 12 units each that build upon the previous unit to develop observing, assessment, and application skills for the educator. In order to complete each unit the computer-aided interactive lesson must be completed with a CLM coach assuring that participants demonstrate the skills developed by the unit. The lessons begin with descriptions of the seven basic learner repertoires and an assessment of a mock learner. Following this are practice sessions of designing instructional delivery with a pretend learner in order to develop fluency in lesson and reinforcement delivery. Continuation of the course delves into the teaching of proper observation, the clear description of observed behaviors, detailed recording of the observed events, and reliability checks with the coach.

Next, the expansion of reinforcement is introduced including different types of reinforcement and predicting the probable effect of reinforcement. Additionally the A-B-C 
relationship of antecedent, behavior, and consequence is established as a tool to precisely define the variables maintaining a behavior. In order to determine if adequate stimuli are present to influence a learner's behavior, the teachers are introduced to the reinforcer survey and the concept of stimulus value, which translates as how specific stimuli may affect a learner's behavior. Following the identification of the worth of stimuli, teachers are instructed on how to condition stimuli to have value for a student in order to have the proper tools to change behaviors.

Subsequent to these tasks, the teacher learns to administer a lesson placement test which measures where a student may fall in the CLM curriculum. After placement is determined the teacher then arranges and runs an instructional session with the student to practice what has been learned in the course of study. Expanding upon the A-B-C information earlier introduced, the teacher sets up behavioral observations over time to gain awareness of a student's 'typical' response patterns in order to determine the probable causes of behaviors. The next step is to develop a program to change the identified behaviors in whatever form may be necessary, carry out the instructional delivery, and then observe the effect to determine if modifications are needed or that instruction can continue as is. The final lesson is continuation and modification of the lesson delivery as needed to influence the student's behavior.

An example of the integration of the CLM into a classroom has been demonstrated through a project completed by Warash, Curtis, Hursh, and Tucci (2008), which used the CLM as a tool to deliver other developmentally appropriate practices in a nursery school setting. In this situation, the nursery school teachers were trained in the CLM course of study and found it to be an effective tool in instructional delivery and behavioral management. The project provided anecdotal evidence of how the CLM was utilized in a preschool setting and the results of the current project offer broader evidence of the effectiveness of the CLM as a tool to inform the development of classroom management strategies.

\section{Theoretical Background}

The background for this study stems from multiple sources. ABA, based on the work of B. F. Skinner, has been a key resource for the development of the CLM, the main tool utilized in the development of the present study (Tucci, Hursh, \& Laitinen, 2004). Additionally, evidence based educational methods, PT, and DI were included in the development of the CLM. The present work has been developed around these theories and tenets of the CLM.

ABA encompasses seven dimensions that make up the theoretical basis of treatment ideology (Wolery, Barton, \& Hine, 2005). Beginning with application, the discipline studies behaviors and issues important to society, of which ASD and inclusion are currently at the vanguard. ABA is, as the name implies, concerned with behavior and its direct measurement rather than making subjective inferences about phenomena. Moreover, ABA is analytical through the utilization of experimental procedures to determine functional relationships between behaviors and other variables. ABA is technological, meaning it is precise in defining operations and variables with operational definitions. Another dimension is that of systematic conceptualization, with experimental treatments and results being contextually relevant to human behavior and understanding. Finally and most importantly, ABA is effective and produces changes in a participant's behavior that are relevant and purposeful.

DI is a highly effective approach to designing curricula and teaching methods developed by Siegfried Engelmann with its first practice and research beginning in the 1960s (Frederick \& 
Hummel, 2004). DI operates under the assumption that all children who have a minimum IQ of 60 can reach content mastery at a reasonable rate if the proper arrangement of variables and conditions is present (Adams \& Engelmann, 1996). School staff members are seen as supporters of a child's learning and are expected to identify and solve a child's academic problems in a timely fashion with the help of DI programming. All published DI programs have been field tested to examine their effectiveness and found to be useful in preschool through high school with both regular and special education students. Project Follow Through, a comparison of 13 different educational models, completed by the U.S. Office of Education showed that DI provided the best individualized instruction and also scored better than all other teaching models in basic skills instruction and cognitive skills acquisition.

PT was similarly developed in the 1960s by O. R. Lindsley who had previously worked with B. F. Skinner (Binder \& Watkins, 1990). Lindsley has based his educational program on the premise that "the child knows best," meaning that if a child has reasonable mental capacity it is the environment that is impeding their learning rather than a lack of cognitive faculties. PT also includes performance assessment measured on a daily basis with the standard celeration chart. Another aspect of PT is the concept of fluency, that not only accuracy but also rate of responding is very important in acquiring skills. Additionally, the acceptance of errors as an integral part of learning along with a tool known as "learning screening" are both concepts from the doctrine. PT has been found to be a successful educational tool evidenced by each individual's learning due to the systematic instruction. The most notable success of PT is the Great Falls, MT study that occurred over a 4 year time period. In this experiment students received 20-30 min a day of PT and increased their standardized test scores an average of 19 to 40 percentile points, depending upon the subscale of the test. This led to the U.S. Office of Education providing funding for propagation of the method via the Precision Teaching Project.

\section{The Current Study}

The present study focused on a single student diagnosed with ASD in a general education kindergarten setting. It was hypothesized that the behavioral intervention would have a positive effect on appropriate participation and a negative effect on inappropriate participation. The time the student was in the autism specific classroom was not included in the study, as the focus of this specific project was the effect of the intervention in the general education classroom.

This project is important and relevant because if the CLM informed intervention effectively increases the appropriate participation and behavior of a child who has a diagnosis of ASD, then perhaps the study can be replicated in an effort to help other children with ASD become more successful in general education settings in order for them to receive the best education possible. As mentioned, the CLM is an evidence-based practice having a solid research based background proving it to be a successful tool for creating competent learners. Showing the CLM to be an effective tool in developing behavioral interventions in a general education setting opens up a new method with sound design for teachers to apply in their classrooms. Hopefully the results of the study will aid in the implementation and dissemination of a successful tool for helping children with ASD to flourish in an inclusive classroom. 


\section{Method}

This study was initially designed for the participant in a nursery school setting, however due to time constraints was not implemented until the student entered kindergarten. Through direct observations by the author at nursery school the student was accessed using the CLM Curriculum Placement Test (Tucci, Shafer, \& Hursh, 2006). It was discovered through this assessment that most difficulties the student experienced at school were due to deficits in the participator repertoire. The manifestations of these behavior deficits occurred when the student was at a non-preferred activity. He many times did not reach a desired level of appropriate participation and in the process disrupted the classroom milieu. Typical behaviors of the student were crying, yelling, refusing to participate in the activity, and not following directions for the activity. After progressing to kindergarten the student was observed for 14 days and the situations and behaviors were found to be very similar to those that had occurred at nursery school. Thus from observations at nursery school and in kindergarten it was determined that the goal of the study would be to focus on the participator repertoire; specifically to increase appropriate participation and decrease inappropriate participation.

The study was a single case design experiment that employed a multiple baseline design and utilized methodology from the CLM to identify behavioral repertoires that needed further development for a child diagnosed with ASD in a general education kindergarten classroom. A multiple baseline design was chosen with the intent of applying a single intervention across multiple classroom activities of the school day using each as a separate baseline. The goal of the intervention was to increase appropriate participation and to decrease inappropriate participation across classroom activities in hopes that the student would be more successfully integrated into the general education class. It was determined from reinforcer surveys and direct observation that adequate stimuli were available to affect behavior change in the student. All data was collected via direct observation and a behavioral intervention based on contingencies described in the CLM was introduced across classroom settings in an attempt to help the learner be more successful in school.

\section{Participant}

The participant in this study was a 6-year-old male, diagnosed with ASD who was selected because of difficulties in fully participating in classroom activities without disruption. Also, the author had previously worked with the student in a nursery school setting, and at the request of the student's parents continued with the student to kindergarten. The diagnosis of ASD was received from a local university hospital's neurodevelopment center. Tests showed that the child had impairments in personal and social functioning, fine and gross motor skills, and communication that met diagnostic criteria for ASD from the DSM-IV (Poe, Jaynes, \& Cobun, 2007). At the time of testing, the participant's chronological age was 55 months; his personal and social ages were less than 12 months; his fine and gross motor skills were at 36 months; and his communication skills were found to be at less than 12 months according to the Battelle Developmental Inventory (Bernot, 2007).

Since being diagnosed with ASD, the participant had taken part in multiple therapies including equestrian therapy, speech therapy, and occupational therapy. In addition to these activities, the child also attended swimming lessons and two different nursery schools prior to 
entering kindergarten. The child's parents were married and both had completed a 4-year college program with one parent finishing a doctor of philosophy degree and another continuing into graduate work. At home the participant had a brother 2 years older than himself and a sister 2 years younger who were both developmentally typical. Moreover, a family history revealed no incidences of any developmental, behavioral, or psychological disorders.

\section{Setting}

The child attended kindergarten five days a week from 8:40 a.m. until 3:30 p.m. at a public elementary school with 22 other typically developing children and this is where the intervention was applied. Included in the daily schedule were morning and afternoon circle time, rotating centers, lunch, recess, math center, art, physical education, music, library, and quiet time. Adults in the classroom with the children were a regular education teacher, an aide, the researcher, and miscellaneous volunteers. Each day, for approximately $30 \mathrm{~min}$ in the afternoon, the participant was in the classroom of the autism specialist participating in various activities with other children who exhibited special needs. All interventions took place in the general education classroom across the different situations of the day.

\section{Measures}

As a means to record the behaviors, a worksheet that can be viewed in Appendix B was developed by the author to collect the data. It was agreed upon by the author and advisor that the first, middle, and final 5 min of each session would be recorded, as this should be representative of the student's behavior over the course of the activity. The data collection sheet consisted of partitions of 5 min intervals that were divided into $10 \mathrm{~s}$ time frames, each with a designated marker for appropriate, neutral, or inappropriate behavior to be selected. The initial $2 \mathrm{~s}$ of each $10 \mathrm{~s}$ time interval were spent viewing the behavior of the student and the remaining $8 \mathrm{~s}$ were utilized to mark the type of behavior observed. To ensure time accuracy, a digital clock large enough to easily view was acquired and could be discreetly set and reset by the researcher. In order to ensure that the final 5 min of each center were recorded, it was arranged that the teacher signaled when approximately 5 min were remaining. This was not necessary for morning or afternoon circle because each of these activities had a designated end time that was consistent from day to day.

The study followed a multiple baseline design, measuring the effects of verbal praise and a token economy system on the incidence of each type of participation across situations. Behaviors measured were categorized into three groups: appropriate participation, inappropriate participation, and neutral participation. Using the CLM as a guide for data collection and organization, the student was observed in the classroom for approximately three full weeks of school (14 school days) in order to determine how behaviors should be classified and what settings seemed the most difficult for the student. From these observations, appropriate, inappropriate, and neutral participation were operationally defined for each of the settings observed and a list of each of the defined behaviors can be found in Appendix A.

Moreover, the anecdotal notes taken during these observations have served to enhance data from later observations. These notes taken before data collection began show what exactly some of the student's appropriate, neutral, and inappropriate behaviors included. All of the behaviors described occurred at some level during the school day, and it was the goal of the 
study to increase, decrease, or eliminate the behaviors. As behavioral categorizations were delineated during the qualitative collection period, it was acknowledged that no student would ever have a $100 \%$ appropriate participation record and so that was never an expectation or goal of the present study for the student. Both appropriate and inappropriate behaviors are broken down into categories to more succinctly describe the comprising actions, though this was not deemed applicable to neutral behavior. All of the following illustrations cite specific examples of what was included under the behavioral categories.

Appropriate participation. After viewing the narrative data from classroom observations appropriate behavior was broken into three behavioral categories: following directions, appropriate verbalizations, and appropriate interactions. An incident of the student following directions occurred when the student retrieved his pencil basket, sat down at the center, and followed the teacher's directions to color his worksheet. Another example of following a direction happened when the teacher clapped a pattern at circle time and the student mimicked the pattern with the class after the teacher completed the pattern.

In regards to appropriate verbalizations, the student sometimes made statements or questions that were irrelevant to the situation at hand creating a disturbance, therefore appropriate verbalizations were an important event that warranted increase. An example of an appropriate question occurred when the topic of the week was school bus safety and the teacher was reading a story about a school bus at circle time, and the student asked, "When will we go on a bus?" As the children were to be taking a bus ride later in the week for a field trip, this was a suitable and relevant question for the subject at hand. Another example of an appropriate verbalization occurred again at circle time when the teacher brought out 'Miss A A-choo' the letter person and the student made the "achoo" sneezing sound. These types of verbalizations show examples of some of the targeted appropriate behaviors.

At times, the student did have difficulties having appropriate interactions with both teachers and peers, but was sometimes able to interact appropriately as shown here. For example, when seated at a table the student verbalized, "I don't have a yellow" to which a peer replied, "You can borrow mine" and the student accepted the crayon and said, "Thank you." Next, the peer asked for the crayon back and the student handed back the crayon saying, "Here you go.” Another example during center time is when the student finished a booklet and took it to the teacher to be stapled; the teacher replied, "No not yet, you need to get the other papers in your mailbox." Proceeding to the mailbox, the student gathered his other papers and took them to the teacher, helped her staple the booklet and walked back to his seat at the table. Once at the table, the student shared his booklet with a peer saying, "Look at this book, it's mine.” These illustrations exhibit that the student did have the necessary skills for appropriate interactions, however not at a desired level.

Neutral participation. This category was not divided into subparts because all of the behaviors seemed to have the similar makeup of the student being physically in the area of activity, but not being particularly on task. One example of this was a recurring behavior throughout the qualitative recording, with the student sitting in circle time in the sunken area, but leaning back on the stair behind his head. When this happened, the student was still physically present at circle time; however he was not engaged with the activity at hand and the behavior was not disruptive to the milieu. More evidence of this category of behavior arose at center time during a worksheet activity. The instructions were to color blue dots on the octopus picture with the goal of learning colors; nevertheless the student colored the entire project brown after the 
teacher had given the directive to color with blue. A similar instance of neutral behavior surfaced during a bingo center. While the student sat at the table, he accepted the materials; but rather than covering the numbers as called with the markers, he just played with the markers on the card with no regard for what the teacher had instructed.

Inappropriate participation. The final category of inappropriate behaviors was operationally defined as disengaged and disruptive, or engaged and disruptive. Inappropriate behaviors could be categorized into four groupings: irrelevant statements or responses, boundary breaking, inappropriate vocalizations, and aggression. One illustration of an irrelevant statement would occur when the student repeated movie lines, which usually resulted in silence or odd looks by his peers, as they did not know how to respond to the declaration. For example, at show and tell the student presented his toy and then declared, "Everybody I'm going to tell a story," and then repeated a line from a movie. The students sat and looked quietly at the student and the teacher directed him to let someone else have a turn. At another time the student was asked what kind of donut he liked at a discussion about donuts, to which he initially acceptably replied "sugar," but then added "and I'm going to be a magician and turn everybody into rabbits." As these types of declarations were atypical and not relevant to any situations at hand, they were targeted as types of behavior that should be decreased.

Boundary breaking was an overt issue and happened when the student would invade another person's personal space or touch objects that were set as off limits. Multiple instances of space invasion occurred during circle times, when the student was in close proximity to peers. Examples of this were blowing, growling, or making animal noises in a neighbor's face. A case in point of handling off limits objects was when the teacher had props set up to use at circle time and the student continued to play with the props after two redirections to not touch the items. Again at circle, a peer was attempting to move a book that was close to the student and the student loudly told his peer to stop. When the peer continued to move the book, the student smacked his hand on the book in order to stop the movement.

Aside from the irrelevant statements and questions the student sometimes posed, he also exhibited some other inappropriate vocalizations. Crying at times that seemed unusual was an issue for the student; such as when he was directed to color a worksheet at a center he replied, "I don't want to" and began to cry. Crying typically resulted from the student being directed to perform a task that was non-preferred. Moreover at times the student would make noises or animal sounds at times when this was distracting to peers, such as when the teacher was reading a story at circle time. Yelling also was a concerning act that was presented by the student. Though the responses typically were relevant to the situation when the student yelled, the tone and volume of his reply was disruptive to the classroom milieu. For example, when directed to line up for the bathroom, rather than telling the teacher he did not need to go at an acceptable volume and tone the student yelled, “I don't want to go!”

The final categorization of inappropriate behavior, aggressiveness, was the most concerning as it presented potential harm to other students. Though the student's behaviors were not seriously dangerous, they were unacceptable. Illustrating a show of aggressiveness, the student shoved hard back into the chair of a peer who had accidentally backed into the student's chair. A further example of aggressiveness showed up during block play with the student and a peer. The children were building and directed to clean up the center, and as the peer started to pick up the blocks the student said, "No, I don't want to" and pushed the peer away. The peer continued to pick up the toys, ignoring the student resulting in the student punching his peer in 
the arm three times. Pushing and hitting were the two most common shows of aggressiveness by the student that were documented.

\section{Accuracy}

After initial classroom observations it was decided that only in class situations would be intervened upon with other activities outside the classroom excluded due to the perceived complication of intervention application. Momentary time sampling was determined to be the most accessible and appropriate system of collecting data through early classroom observations. Measures of appropriate, inappropriate, and neutral participation were taken, with results for the type of participation converted into percentages as the opportunities for participating varied across situations. Each circle time, morning and afternoon, lasted between 30-45 min and had the first, middle, and final 5 min as times when data was recorded. Rotating centers lasted approximately $60 \mathrm{~min}$ and had three choice areas divided into 20 min segments with only the first and final 5 min as data recording times. Five min time intervals were chosen as a feasible way to record the participation data while allowing glimpses of participation during different times of the activities.

The author completed training in the CLM course materials and performed data collection. The training included introduction to the basic tenets of ABA, DI, and PT and how this information could be used in an educational setting (Tucci et al., 2004). Additionally, the CLM course of study instructed in detail how to observe behavior, record data, and apply practices. The course of study consisted of 12 units, previously described, which covered in great detail specific aspects of learner assessment, data collection, lesson delivery, stimuli evaluation, and application of conditioning stimuli as reinforcers (Tucci et al., 2006). Learning materials for each unit included a binder of materials, computer based coursework, video training, and hands on trial and error practice. After each unit was completed the author checked out with her coach, a Board Certified Behavior Analyst who either signed off on the unit or made suggestions for changes to be made and then reassessed the unit until completion. This work provided the author with adequate and dependable data recording capabilities.

Data was collected through direct observation with recording done on the worksheet designed for the study. Assisting in the data collection were two graduate students who were trained to observe and collect data for the accuracy aspect of the project. In regards to training observers for accuracy checks, the first step was to define and agree upon operational definitions of participation for each situation; which have been delineated in Appendix A. Moreover, the classroom teacher was given the operational definitions to review to ensure agreement of behavioral expectations and remained an active participant in this process throughout the study. The next step in developing accuracy and was through mock analyses of previously recorded data. Training was comprised of watching videos of the participant in a past nursery school setting and these videos were utilized as a means of teaching what encompassed appropriate, inappropriate, and neutral participation. Prior to the collection and analyses of any data used in the actual study, the collectors practiced on a minimum of five of each of the video recorded situations until an $80 \%$ agreement rate was reached. In the case that agreement did not attain an acceptable standard, the operational definitions were returned to and revised to more precisely fit the behaviors. Practice then continued until both parties reached the predetermined agreement rate of $80 \%$ or greater. 
All data was collected and analyzed by the author through observation and the creation of a written record of each activity as it occurred daily. The author collected the data daily and for each situation being intervened on accuracy checks were completed weekly. Every week that data assessment occurred both morning and afternoon circles were observed with other situations being observed only intermittently. Inter-observer agreements were obtained consistently only on the situations intervened on due to limited availability of observers and the assumed importance of accuracy during intervention application. Ascertaining the highest level of agreement was very important, thus agreement was assessed using two different calculations, a point-by-point ratio and kappa. The point-by-point ratio assessed interrater reliability by comparing the number of agreements and disagreements during class. To calculate the point-by-point ratio, the total number of intervals was divided into the total number of agreements of behavior occurrence for an overall agreement ratio. Kappa corrected for chance agreement and subtracting the number of possible chance agreements from the point-by-point total completed computation of this statistic. Checks on agreement were calculated twice per week and needed to reach a minimum level of $80 \%$ for each agreement type to be considered adequate (Kazdin, 1982). For four weeks over the course of data collection checks on accuracy were not completed due to absences of the researchers owing to holiday breaks from the university or outside circumstances. To sustain the acceptable amount of agreement, a debriefing session for the observers occurred every day of data recording or at any time either observer had a concern or question. All questions were referred to an advising professor who contributed to the development of the CLM course and was a Board Certified Behavior Analyst. Furthermore, a record of how often the teacher delivered verbal praise with each sticker was recorded to ensure treatment fidelity. Unfortunately, this recording did not occur continuously until discussion happened upon the need for documentation of this data, whereupon a continuous record of the information was kept.

\section{Teacher Training}

A private instructional session with the lead teacher was used to convey the intervention information with a brief synopsis of the study given explaining the behavioral plan and intentions and hopes for the student's development. Likewise, an explanation of how reinforcement has an effect was delineated. Instruction was given on when and how often the teacher should deliver praise and sticker reinforcement to the student. Included in the instruction was daily help by the author who presented a visual cue for the teacher indicating when to deliver reinforcement. Moreover, specific instructions on how to avoid reinforcing inappropriate behaviors were covered. Avoiding any type of reinforcement or attention for $15 \mathrm{~s}$ after the learner exhibited an inappropriate behavior ensured that these behaviors were in no way reinforced. Coupled with these face-to-face instructions was a "cheat sheet" for the teacher to refer to in the form of a small laminated card with reminders for how to respond to the student's responses. After intervention began, feedback was delivered daily concerning any needed changes and allowing for questions. Moreover a refresher session for the teacher going over everything that was covered in the initial teaching session was given during Intervention 2 of Morning Circle to help ensure that the teacher maintained the reinforcement delivery correctly.

\section{Reinforcement}

To ensure that reinforcement was sufficient, the participant's parents filled out a reinforcer survey identifying tangible items, social reinforcers, and activities that the child enjoyed. Additionally, the autism specialist conducted a survey supporting the use of stickers as tokens and found other valuable reinforcers for the learner. From these surveys and author 
observations, it was decided that verbal praise and Scooby Doo stickers should be used as reinforcers for the study. Furthermore, to make certain that stickers did not lose their reinforcing value from overuse, a token economy with the stickers was utilized. A laminated card to collect the stickers on was made for the student with a grid containing the exact number of spaces that needed to be filled to earn further reinforcers. Once the student garnered the determined number of stickers, he was able to choose among nine valued activities: play-dough, marker drawing, Mr. Potato Head, a green swing, a scooter, computer time, flarp, moon sand, or a bouncy ball and popper.

Design

Using the multiple baseline design, the effects of verbal praise and sticker reinforcement on participation across different situations in the classroom were measured. During this time, the child's peers continued with normal daily activities while the intervention was implemented. Praise and stickers were delivered for appropriate participation while inappropriate or neutral participation were not reinforced with the expectation that these behaviors would be replaced with appropriate participation through differential reinforcement. Differential reinforcement can be defined as the reinforcement of any specified appropriate behavior and the withholding of reinforcement for any specified inappropriate behavior, in the hopes that the reinforced behavior will replace the unwanted behavior (Heward, 2006).

Baseline. Baseline consisted of the child participating in typical school activities with no intervention applied; only the normal reinforcement that was offered for any child was available. Baseline data was recorded for 20 days for all situations, whereupon it was determined from visual analysis that Morning Circle was the situation where the student had the least amount of appropriate participation and the most stable pattern of behavior. When the intervention began at Morning Circle all other classroom situations were maintained at Baseline with no intervention. Moreover, multiple situations were kept as continuous baselines in order to show support for the intervention effect. Continuous baseline situations consisted of Rotating Center; Brown Table Center; Yellow Table Center; Afternoon Center; and Specials, which was comprised of Music, Library, and Art.

Intervention 1(Morning Circle). Prior to Baseline, it was decided that reinforcement would be verbal praise paired with stickers to be used as tokens to earn further rewards. A trial and error method was utilized to determine how many stickers would need to be earned in order to gain preferred activities. Beginning with five stickers it was found that this was an amount that was attainable for the student, yet was not too easily garnered. Intervention 1 began 21 days after the start of Baseline, with stickers and praise delivered to the student via the lead teacher, who was cued by the author when to administer the reinforcement. In order to ensure the student's success, reinforcement was given promptly when the student exhibited what had been determined an appropriate behavior. Moreover, all days of intervention except two, the author presented the student with his sticker card before Morning Circle and reminded him of the behaviors needed to earn stickers. The conversation included showing the teacher he was listening by looking at her, singing songs or repeating after the teacher when asked, sitting up straight rather than laying back on the stairs, and keeping his hands to himself rather than playing with peers.

When Morning Circle was over and the student had earned all five stickers, he would bring the card to the author who would take him to the activity choice area that had been set 
aside in the classroom. At this time he was able to choose any activity from the nine available and play for a period of $1 \mathrm{~min}$. One minute was chosen through experience in the autism classroom as a time period that allowed involvement in the activity at hand, but not to the extent that it created a problem for the student when returning back to regular classroom activities. Following the 1 min of playtime, the student would rejoin the class in whatever activity was now at hand.

Intervention1 (Afternoon Circle). After the intervention was applied during Morning Circle, it was determined from further examination of data that Afternoon Circle was the next setting most in need of an increase in appropriate participation. Intervention began in Afternoon Circle after 38 days of Baseline exactly as it was applied in Morning Circle. Everyday before Intervention 1, as with Morning Circle, the author went over the expectations of how to earn stickers with the student when giving him his sticker card. After each instance of appropriate behavior the teacher, as visually cued by the author, gave a sticker and verbal praise to the student. The student again needed to garner five stickers and upon completion of circle time was then able to exchange the sticker card for 1 min of a preferred activity. Following this activity time, the student again joined the class for whatever activity was occurring.

Intervention 2(Morning Circle). Following an increase in appropriate behavior after Intervention 1 during Morning Circle, the author surmised that the student's appropriate behavior could increase more. It appeared that once the student had earned five stickers, his behavior for the remainder of Morning Circle was somewhat off-task, generally falling into the neutral behavior category. It was hypothesized that if the final sticker was not delivered until the final 5 min of Morning Circle then perhaps the student's appropriate behaviors would increase more.

In response to this theory, at 27 days after Intervention 1 began, Intervention 2 was implemented at Morning Circle. The intervention was the same as before with verbal praise and five stickers being dispensed; however rather than being given at the first five instances of appropriate behavior the reinforcement was given across the entire time period of Morning Circle with the final sticker not being delivered until the final 5 min of Morning Circle. After the student earned the five stickers, he was then able to exchange them for $1 \mathrm{~min}$ of a preferred activity after which he rejoined the class at their present task. 


\section{Results}

Visual analysis of the data showed that the intervention did appear to have the effect hypothesized of an increase in appropriate participation and a decrease in inappropriate participation for both situations to which intervention was applied. Neutral participation was recorded but was not included on the graphs for ease of viewing purposes. Also, appropriate and negative participation appeared to be inversely related so it was decided that neutral participation did not add an important amount of additional information to the graphs. Figures 1 and 2 are of the classroom activities intervened on, Morning and Afternoon Circles respectively. The remaining Figs. 3-9 show the occurrences of behavior for the activities that served as baseline comparisons. The activities that served as continuous baselines have been broken up into four phases that correspond to baseline of Morning Circle (Phase 1), Intervention 1 at Morning Circle (Phase 2), Intervention 1 at Afternoon Circle (Phase 3), and Intervention 2 at Morning Circle (Phase 4). Additionally, a data table can be viewed in Appendix C showing the statistical information for all classroom situations.

As can be viewed in Fig. 1, during Morning Circle appropriate behavior was on a slight downward trend (-..30) during Baseline and then reversed to a positive direction (.63) at Intervention 1 with a change in slope of .93, as derived from the trend line from a regression analysis. Moreover, during Intervention 2 behavior again exhibited a positive trend though showed a slight decrease to a slope of .56. Similarly, at Afternoon Circle the trend transposed from a negative slope during Baseline to a positive slope at Intervention 1 with an overall change of 1.43, which can be viewed in Figure 2. Additionally, both Morning and Afternoon Circle showed decreases in negative participation as positive participation increased as intervention was applied. Figures 3-9 show that the slopes of four of the continuous baselines Rotating Center, Brown Table Center, Afternoon Center, and Library exhibited positive trends during Phase 1; while Yellow Table Center, Art, and Music showed negative trends in appropriate behavior. Amongst the continuous baselines, the trends varied from positive to negative slopes with no apparent relationship to the interventions applied during Morning and Afternoon Circles over the course of the study. 


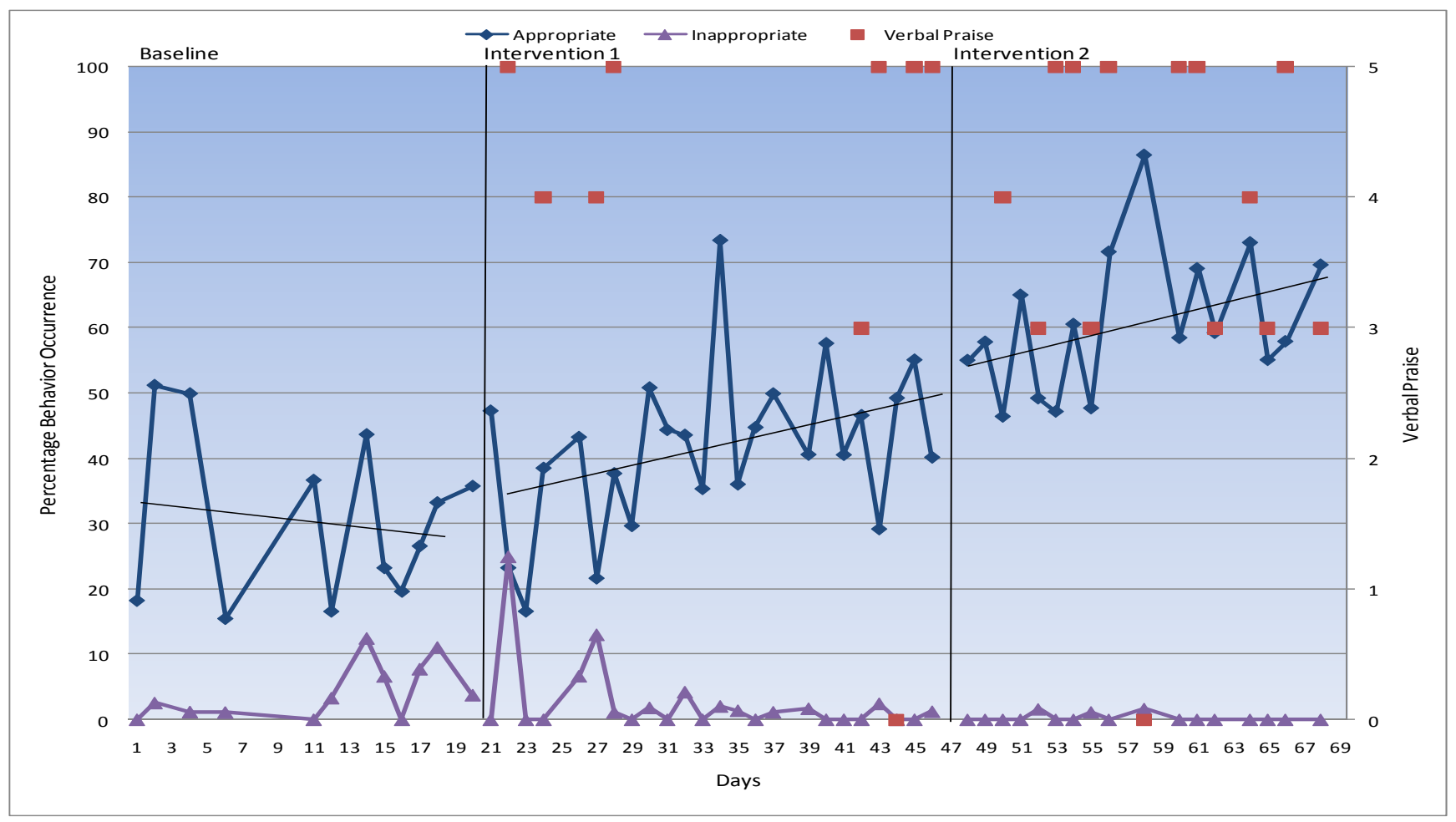

Figure 1. Percentage of appropriate and inappropriate behavior occurrence at Morning Circle.

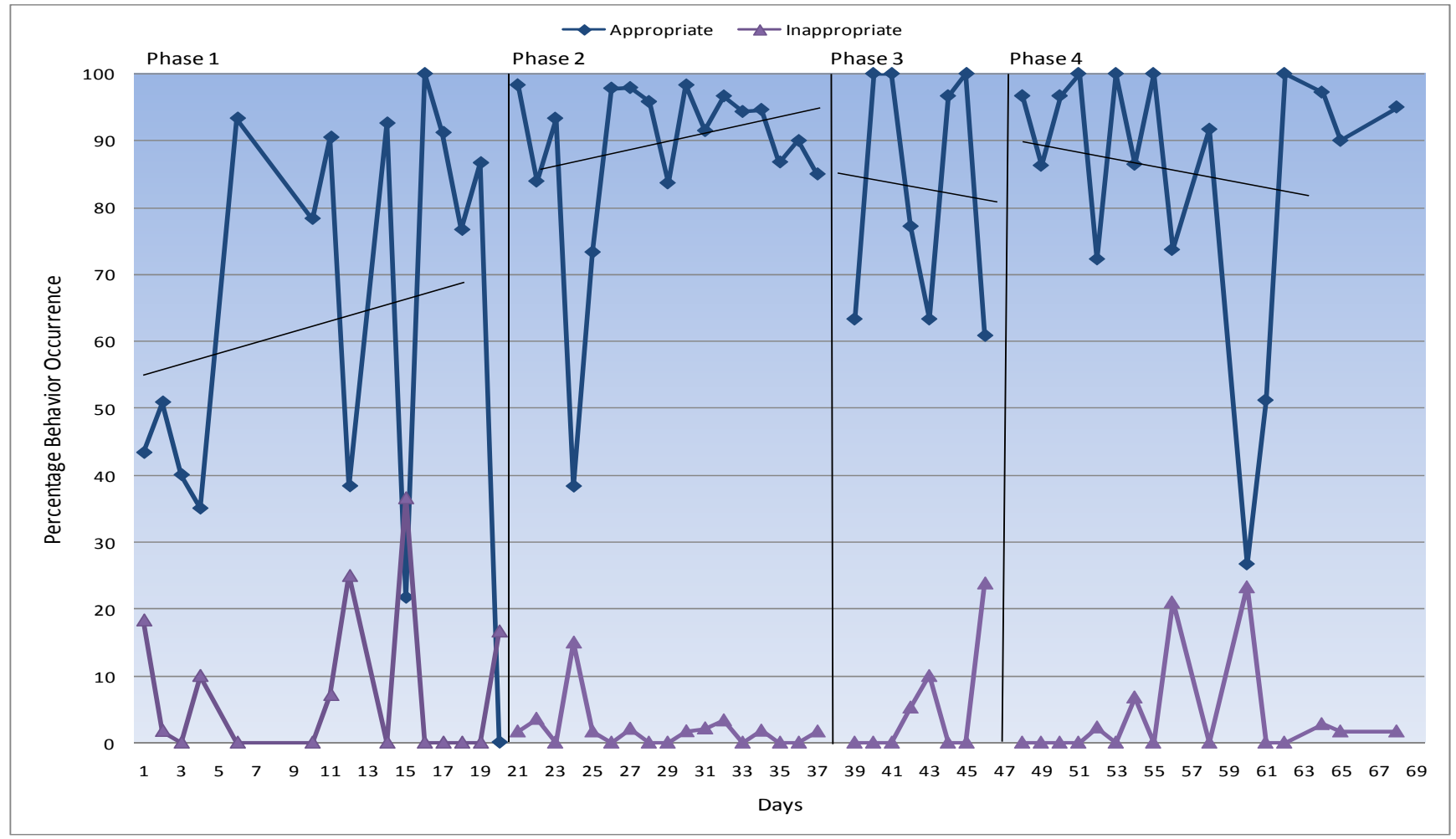

Figure 2. Percentage of appropriate and inappropriate behavior occurrence at Rotating Center. 


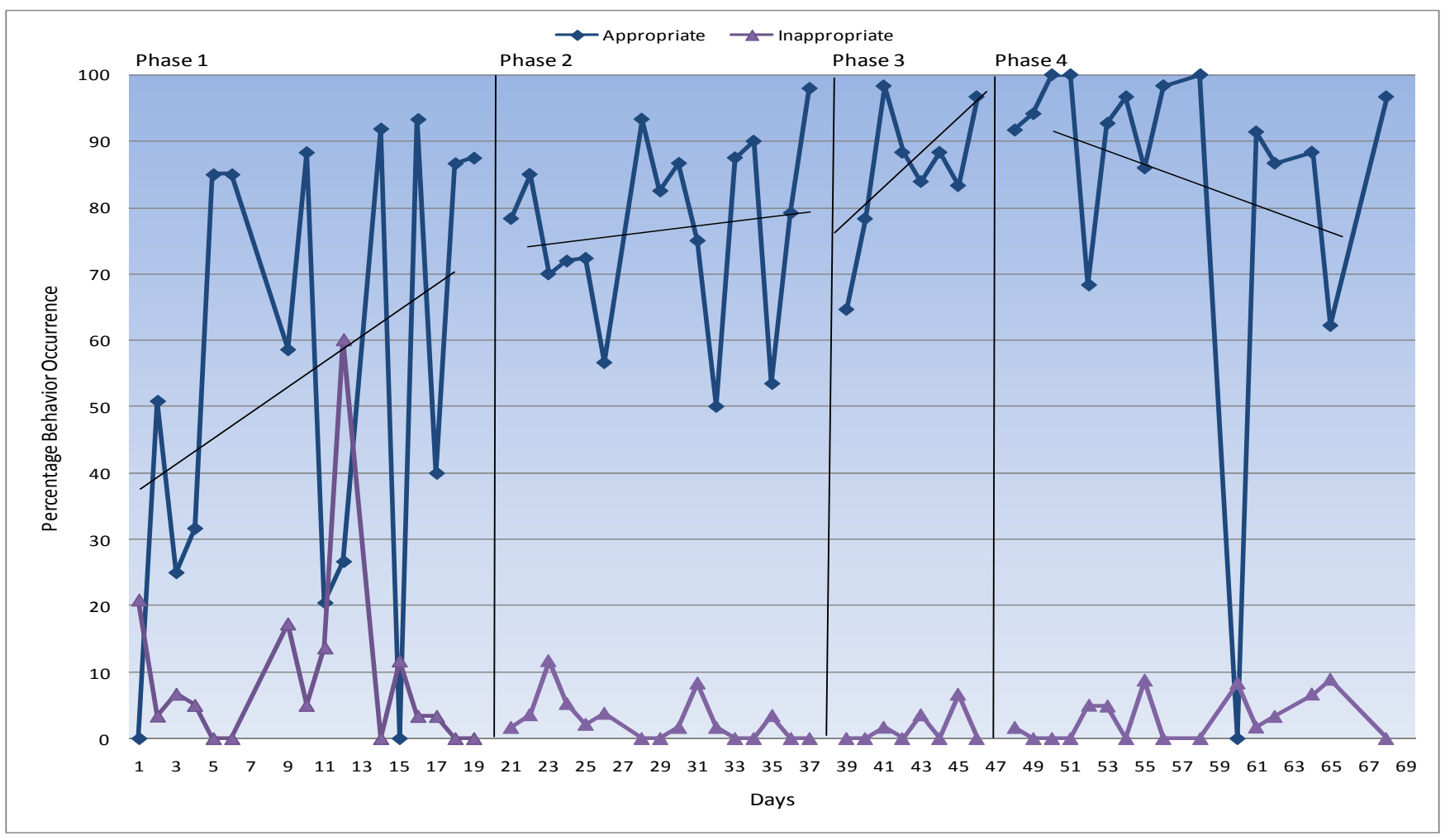

Figure 3. Percentage of appropriate and inappropriate behavior occurrence at Brown Table.

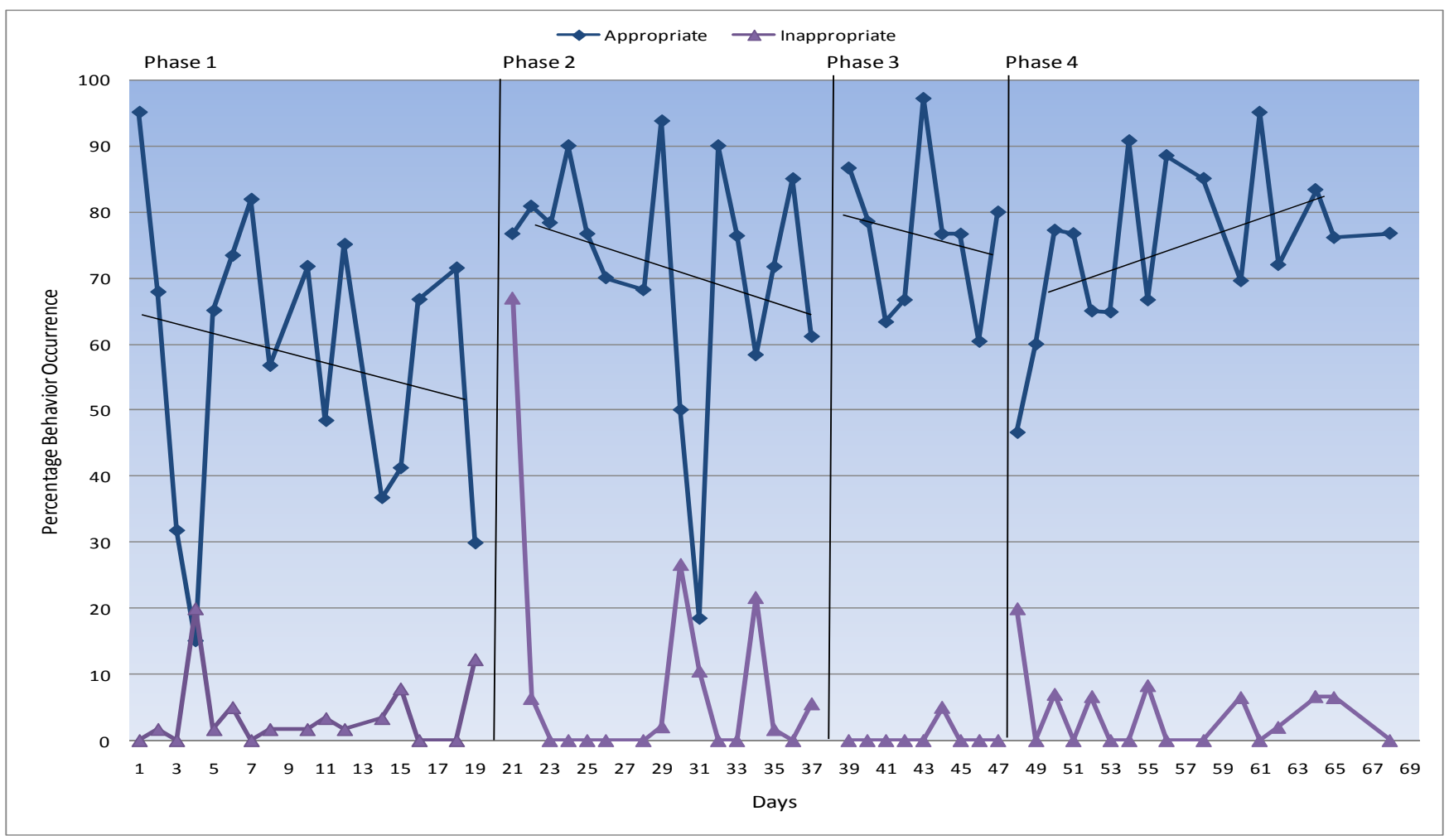

Figure 4. Percentage of appropriate and inappropriate behavior occurrence at Yellow Table. 


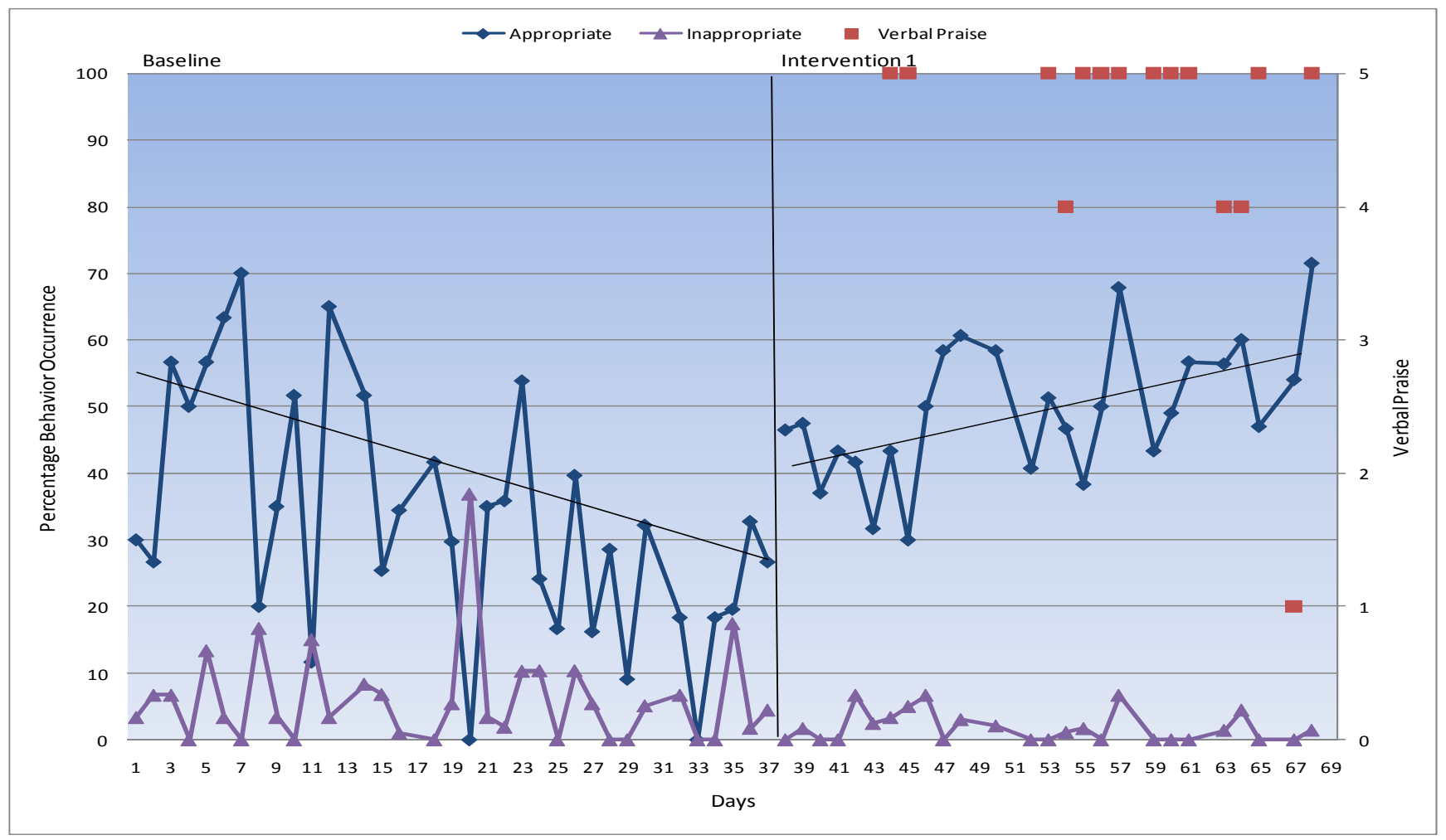

Figure 5. Percentage of appropriate and inappropriate behavior occurrence at Afternoon Circle.

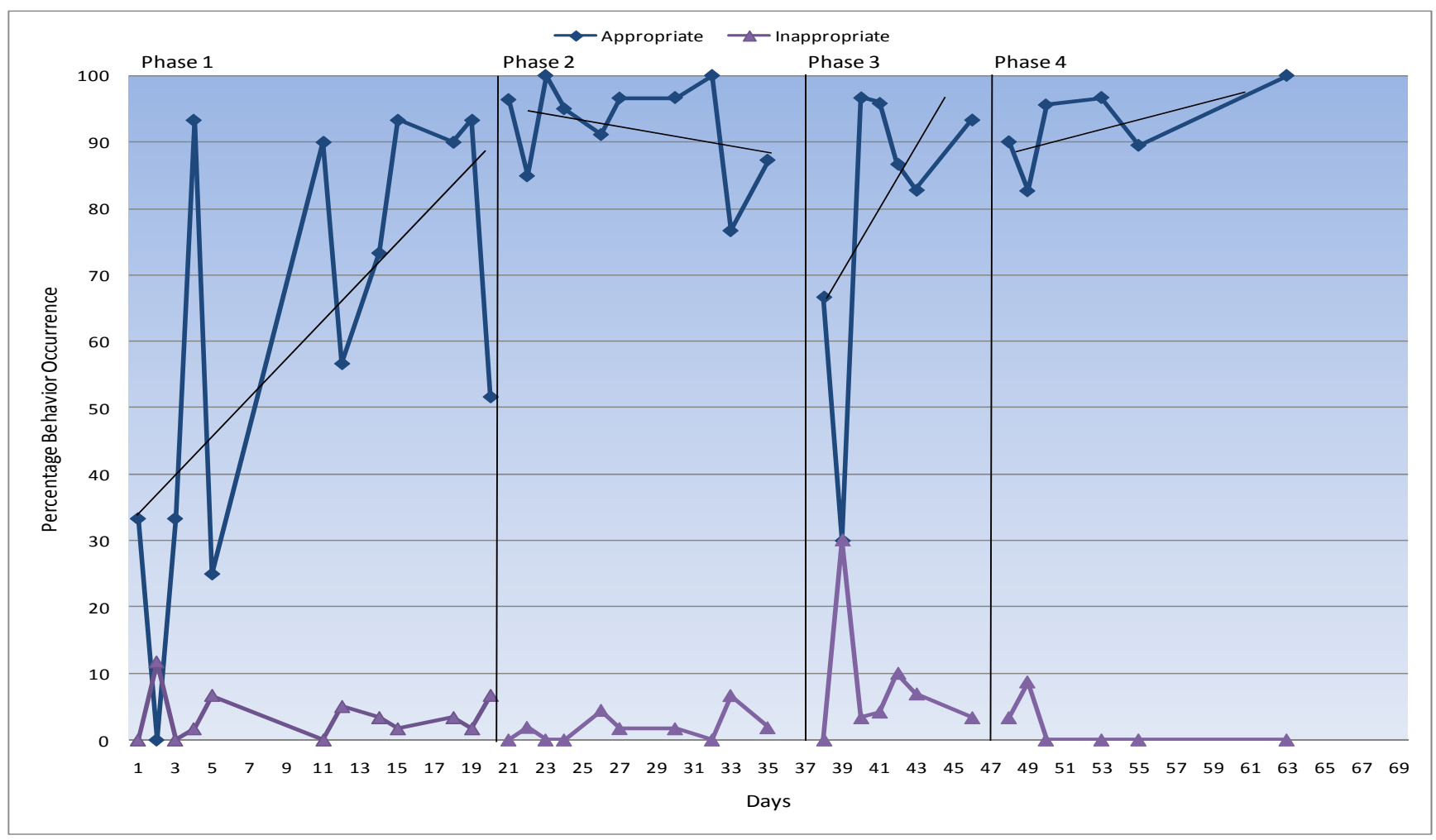

Figure 6. Percentage of appropriate and inappropriate behavior occurrence at Afternoon Center. 


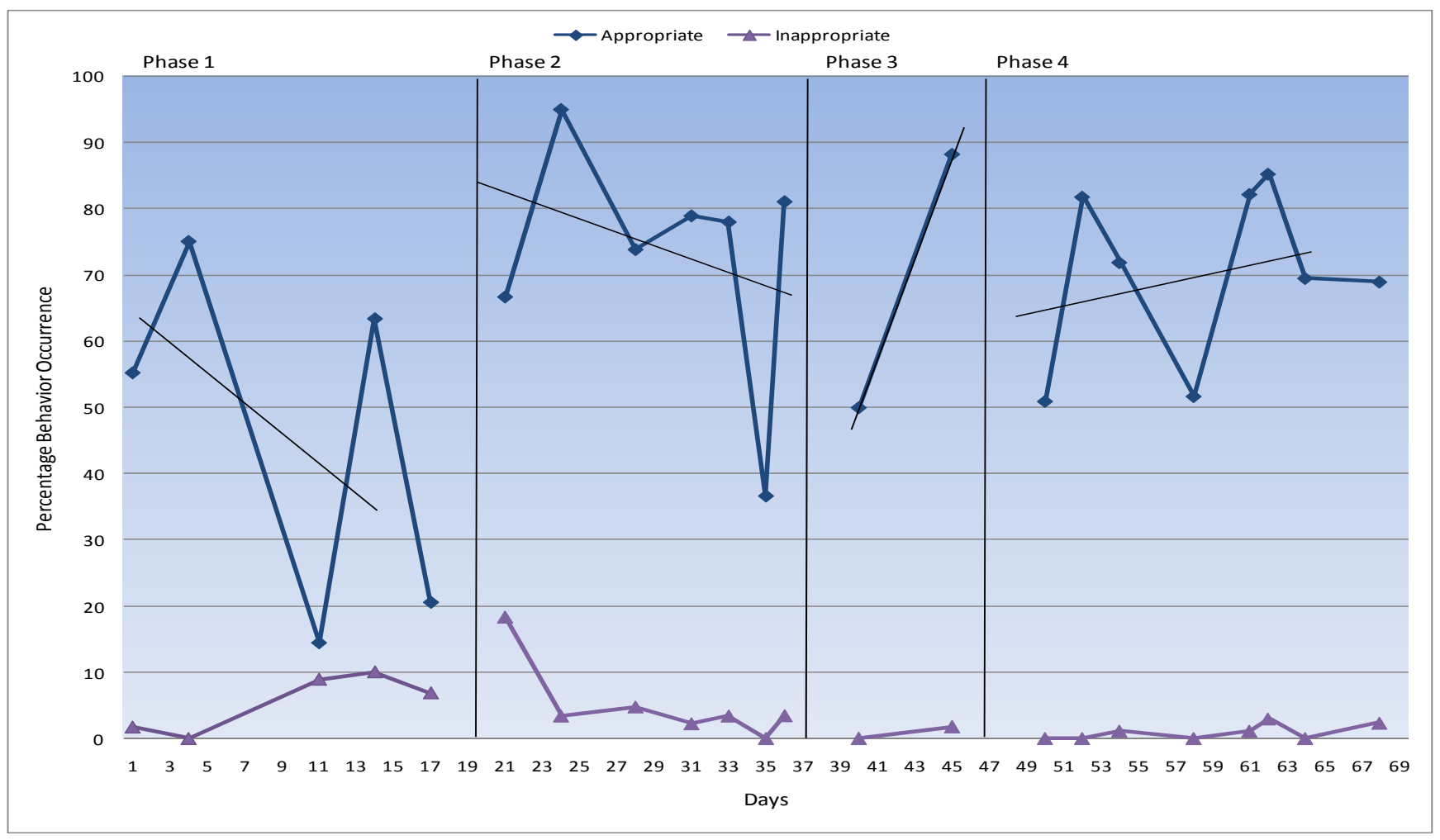

Figure 7. Percentage of appropriate and inappropriate behavior occurrence at Art.

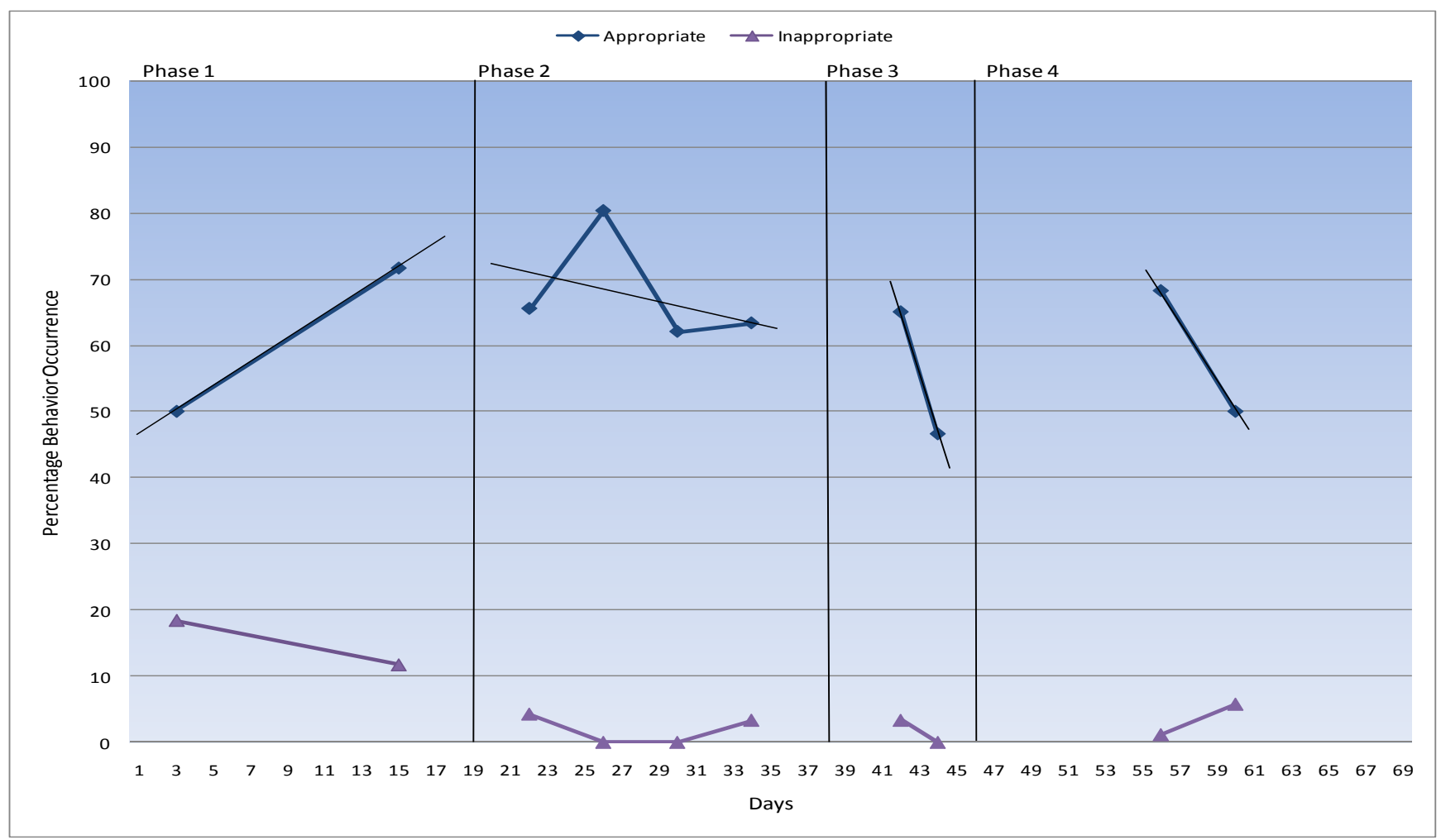

Figure 8. Percentage of appropriate and inappropriate behavior occurrence at Library. 


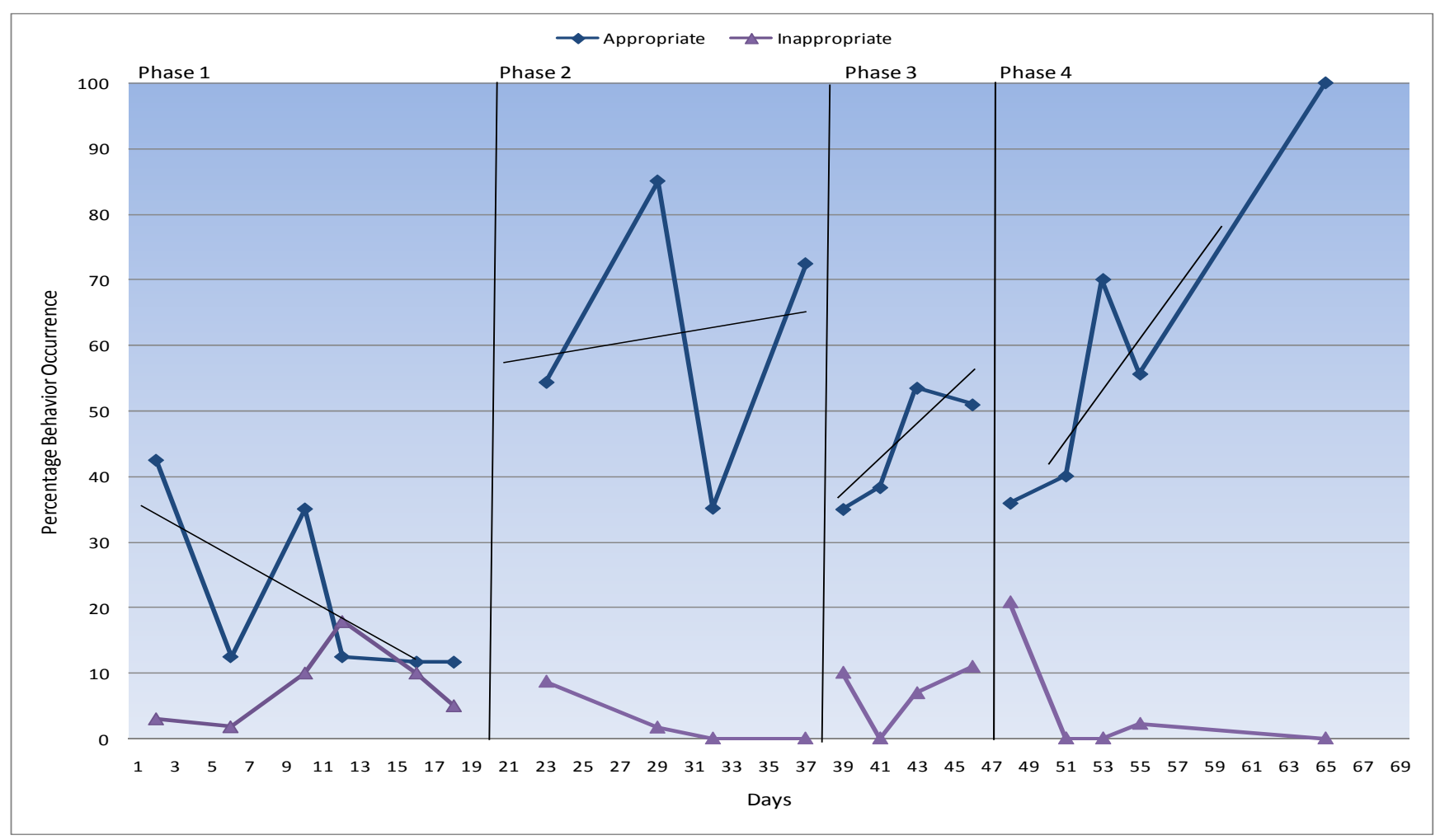

Figure 9. Percentage of appropriate and inappropriate behavior occurrence at Music.

In further support of the intervention effect, the mean occurrence of appropriate behavior increased from Baseline to Intervention for both Morning and Afternoon Circles. Morning Circle went from a mean occurrence of appropriate behavior of 30.94 during Baseline to 41.55 at Intervention 1, and showed another increase to 60.93 during Intervention 2. Correspondingly, Afternoon Circle showed an increase in mean of 21.19 points from Baseline to Intervention 1. Interestingly, all continuous baselines illustrated an increase in mean from Phase 1 to Phase 2. However, at subsequent phases the means did at times drop for all included continuous baselines, though none sank as low as any of the initial means in Phase 1.

To add further depth to the information, the change in SD was calculated for each situation in order to show the variability and change in variability with the application of the intervention. Morning Circle showed a slight decrease in SD between Baseline (12.27) and Intervention 1 (12.07) of .2 points and another decrease of 2.12 points from Intervention 1 to Intervention 2 (9.95). These small changes in the SD of Morning Circle lead to the notion that the intervention may have had a small effect on decreasing the variability of behavior in Morning Circle. Further evidence from Afternoon Circle shows a decrease in variability from Baseline (12.58) to Intervention 1 (8.45) with a decrease in SD of 4.13 points. All but one of the continuous baselines showed a decrease in variability from Phase 1 to Phase 2; however further phase changes showed unpredictable adjustments in SD. There was no apparent relationship between the interventions of Morning and Afternoon Circles and the changes in SD of the continuous baselines. This leads to the postulation that the intervention may have had an effect on decreasing the variability of behavior.

A final statistical support of the intervention effect is level change between phases of the project, derived by finding the difference from the final point of one phase to the first point of 
the next phase. Morning Circle showed an increase in level change of 11.52 points from Baseline to Intervention 1 and another increase of 14.76 points between Interventions 1 and 2, supporting the effect of the intervention. Likewise, an increase in level (19.81) occurred during Afternoon Circle from Baseline to Intervention 1, again supporting the effect of the intervention. In regards to the continuous baselines, all but two (Brown Table and Library) showed an increase in level from Phase 1 to Phase 2; however changes in level were not uniform at further phase changes with some situations showing increases while others showed decreases. This information supports the view that intervention was responsible for the changes in level at both Morning and Afternoon Circles.

In regards to accuracy, checks were completed twice weekly for the situations being intervened upon with other situations checked as well. Inter-rater reliability was assessed via the point-by-point ratio and kappa coefficient. An overall point-by-point ratio of .94, with a range of .77 to 1.0 , was reached well exceeding the .80 goal to be considered reliable. Additionally the kappa coefficient, which adjusted for chance agreements, came to a total of .87, with a range of 0.0 to 1.0, again surpassing the .80 benchmark, needed to be considered as reliable.

To assess fidelity of treatment, data was recorded noting the number of times that verbal praise was paired with the giving of a sticker for appropriate behaviors, nearly all records show that praise was given with four or five of the stickers. Two incidences did occur when no verbal praise was given at all, one when a substitute teacher applied the intervention and the other day simply has a notation that no verbal praise was used, without any reason given for this lapse. In However, because no data concerning the effect of verbal praise was collected during baseline to compare this data to, no inferences can be made about the effects of verbal praise on behavior. It can just be stated that the teacher was usually providing the verbal praise with the sticker delivery, following the procedure she was asked to follow. 


\section{Discussion}

Upon visual and statistical examination of the data presented, it appears that the token economy system of stickers and verbal praise did have a positive effect on the student's appropriate participation and a negative effect on inappropriate participation as hypothesized. Some caveats are discussed that may have played a role in the change in behavior and could detract from the intervention effect. Overall though, the change in behavior appears to have come from the intervention.

The change in direction of trend between Baseline and Intervention 1 for both Morning and Afternoon circle supports the likelihood that the intervention was at the root of these changes. As it was, there appeared no apparent pattern in the trends of the continuous baselines throughout the study, and the only sessions to show positive trends for the duration of the project were those intervened upon. An alternative reason for the change in trend from Baseline to Interventions for Morning and Afternoon Circles could be that the initial novelty of the activity wore off as school progressed and the student showed less appropriate behaviors because of a lack of interest. Also the expectations from the teacher became more stringent as the school year progressed, which could have had an effect on appropriate behavior.

The mean presents an interesting change in the data because at Intervention 1 of Morning Circle all situations showed an increase in mean. This suggests that either the Intervention had a fairly potent transfer effect, or that some other variable played a role in this increase. It is surmised by the author, that both time and the intervention affected these changes. An important notation to include may be that Intervention 1 did encompass both a 1-week Thanksgiving Break and a 2-week Christmas break. Although this phenomenon may detract from the intervention effect, the increase in mean from Intervention 1 to Intervention 2 at Morning Circle does suggest that the intervention was related to this change; as no uniform increase occurred during this time across other activities with some even showing drops in mean from the corresponding Phases 2 and 3 (Figs. 3-9).

The decreases in SD at the intervention for both Morning and Afternoon Circle support the intervention effect showing a more dependable behavioral pattern. However, the SD of nearly all other continuous baselines did decrease from Phase 1 to Phase 2, possibly indicating an effect of some other variable; conceivably maturation over time or perchance the student adjusting to the school routine with his behavior becoming less varied. Throughout the rest of the study there were no more uniform changes in SD with some activities showing increases in SD while others showed decreases.

Level change served as a final tool to examine data and showed support for the effect of the intervention at both Morning and Afternoon Circles. At the application of each intervention for both settings the level change was positive from the end of one phase to the beginning of the next. Furthermore, the continuous baselines did not show uniform changes at these times, indicating that the level change was likely due to the interventions. Rotating Center, which follows Morning Circle showed a positive level change of 98.33 points at the onset of Phase 2 (corresponding to the start of Intervention 1 of Morning Circle); however it should be noted that the previous day's occurrence of appropriate behavior was 0 , which had not occurred prior to that nor occurred at any point afterwards. It was noted in the anecdotal evidence that at the time 
of this Rotating Center, the student had been directed to take off his hat and would not do so and then isolated at a table quietly refusing to take off his hat or do his work, thereby having only inappropriate and neutral behaviors indicated for this center. It is apparent then that this large level change is not indicative of a transfer effect of the intervention.

Though some factors other than the intervention have been touched on it is important that limitations to the study be fully discussed. On Day 2 due to a lack of prompt reinforcement by the author and teacher the student did not earn all 5 stickers within and then again the next day at Morning Circle the student did not earn all five stickers because of being late for school and only being present the final 5 min of the activity. These lapses however did not appear to have a negative affect on his opinion of the system as he appropriately received the sticker card the next morning at circle time. In fact the low occurrences of appropriate behavior during these days show a support for the intervention effect as the appropriate behavior instances on prior and subsequent days surpass these amounts. Also over the course of the study, holiday breaks occurred where the student was out of school for 1-2 weeks, which could have had an effect on his behavioral performance. What is more, the maturation effect of time should be considered as a potential factor in the change of overall behavior.

Additionally, the type of the setting also had an effect on the student's behavior with more independent activities showing higher rates of participation. Data collected during the project that can be viewed in Appendix D showed that the student exhibited higher rates of appropriate behavior during activities that allowed for more independence. Activities that reached an $80 \%$ rate of appropriate behavior are highlighted in yellow, and it can be seen that Afternoon Center shows the most highlighted areas (78.78\%), followed by Rotating Center (65.52\%) and Brown Table (60\%), and Yellow Table (25.42\%) showing the fewest highlighted areas. Afternoon Center was usually a math center where some type of manipulative was presented to the student and he was expected to sort them according to a teacher directive. Once the teacher gave the instruction for sorting they moved to another table and the student was able to work independently for the remainder of the center. Preference for the Rotating Center was supported by anecdotal evidence such as the student repeatedly asking to go to a specific center during the day and vocalizations of "Ohhhh" and "I don't want to" in response to being directed towards a less preferred center. Rotating Center, as the name implies, was an alternation of multiple centers including play dough, blocks, practice basket, computer, write-around the room, and an alphabet manipulative activity. After receiving a directive, the student was able to then independently work for the remaining time period. Activities that were more teacher-directed showed lower rates of appropriate behavior as can be viewed in Yellow Table Center, which was the most intensive center of literature and language led by the teacher. Some inappropriate behaviors linked to the support of Yellow Table being a non-preferred activity are exclamations such as "I don't want to go to Mrs. R," which were recorded during observations before Baseline. With these pieces of information it is believable that activity type did play a role in the rate of appropriate participation. Based on these findings, it can logically be assumed that some variation in appropriate behavior during circle times could be attributed to the activity during circle time. For example, when the student was the helper of the day at Morning Circle these happenings constituted both of his two highest occurrences of appropriate behavior.

If this study were to be replicated a few changes could be made that may improve the overall results of the project. A more detailed record of verbal praise could be kept, not beginning in the middle of intervention, but at the beginning so as to be able to more accurately 
assess its effect. In an effort to diminish this weakness, qualitative data was reviewed for instances of verbal reinforcement by the teacher during circle times; however only five instances of verbal praise were noted as the student's behaviors were what were mainly recorded. These five instances of verbal praise are similar in nature to those recorded in the ABCs of reinforcement later in the study including: that's right, that's good, thank you, and kiss your brains. With more complete collection of praise data throughout the study the variable could be more accurately assessed in actual value as a reinforcer and also in effectiveness as a reinforcement tool.

An important point to note is that the effectiveness of the CLM was not directly measured in this study. However, the CLM did inform the development of the intervention, the observations, and data collection skills of the author who was trained in the method. Additionally the training of the graduate students who aided in data collection was according to CLM standards. As far as the intervention is concerned, it could have been developed by any person trained in ABA techniques. However the behaviors to be intervened on were chosen according to identified CLM repertoires which are specific to that model.

Furthermore, in regards to record keeping, the instance of each sticker given should be recorded with the ABCs noted so as to ensure that application of reward is appropriate, and to more precisely know the schedule of reinforcement. During the present study, initially it was discussed that reinforcement was 'immediate' during Intervention 1 for Morning and Afternoon Circles and then changed to 'delayed' at the onset of Intervention 2 at Morning Circle. However, after further discussion of the subject it was discovered that the schedule of reinforcement was not as precise as had originally been thought. At the onset of Intervention 1 any clearly appropriate behaviors were reinforced with a sticker until the goal of five was met, as the student's appropriate behaviors were not frequent. However, as time progressed and appropriate behaviors became more common, stickers could be given at a less immediate rate. As time advanced, the author noticed that the student had discovered that after earning his maximum number of stickers his behavior became more neutral than appropriate; as if he had learned that once he earned his five stickers he did not need to be on task any longer to receive his preferred activity. This observable fact led to the assumption that the final sticker could be given later in circle to further increase appropriate participation later into the activity. Thus the application of Intervention 2 was applied with the change that the final sticker would not be given until the end of the final 5 minutes of circle. Additionally, at this time the ABCs of each sticker application and time of occurrence began to be recorded. In further use of this tool it would be wise to record the time and ABCs of every application of reinforcement, so as to more accurately depict the schedule of reinforcement so manipulations and conclusions may be more precise.

Due to time constraints follow-up data was not able to be collected to show if the interventions had a lasting effect. If this study were to be done again, follow-up data checks could be done to clarify whether or not the effects of the study were permanent or transient. This information could lead to potential modifications in future studies and simply more information about the intervention effect. Another future direction for replication studies would be to perform this experiment as a mixed-methods design. Qualitative data taken during pre-baseline shows that this study could have had qualitative data recorded throughout to add depth of information to the results. In the future along with the person collecting quantitative data, another observer could simultaneously record a narrative of events, thus providing a rich breadth of information 
and potentially a more effective intervention tool to increase the beneficial results for the participant.

The overall success of the project shows that the behavioral intervention had a positive impact on the student's school performance. It lends further support to the use of ABA tools in the classroom, and more specifically to the utilization of the CLM as an effective tool in the development of behavioral and instructional management plans for the classroom. Through the CLM course of study the author learned how to effectively and objectively observe and classify behaviors in order to develop a useful system of behavior modification, specifically tailored for one student with ASD in a regular education classroom. Utilizing the intervention program in the general education setting shows that the CLM is not a system that is too complicated to be put to use in a regular education classroom. Once an educator learns the tools of the CLM they can be put to use for any student. The next step in the process of integrating the CLM into use in the classroom would be for a lead teacher to develop and administer whatever behavior modification program may be necessary to make their classroom more inclusive and successful. The integration of this tool shows support for the theories of ABA, PT, and DI as successfully applied to education. Potentially the use of the CLM as a tool for developing classroom management and instruction could lead to more fluidly functioning inclusive classrooms, and provide a feasible avenue for educators to make their classrooms compliant with new laws. 


\section{References}

Adams, G. L., \& Engelmann, S. (1996). Research on direct instruction: 25 years beyond DISTAR. Seattle, WA: Educational Achievement Systems.

Binder, C., \& Watkins, C. L. (1990). Precision teaching and direct instruction: Measurably superior instructional technology in schools. Performance Improvement Quarterly, 3(4), 7496. Retrieved from WVU Library Electronic Journals database.

Bernot, B. J. (2007). Monongalia county schools evaluation report (Evaluation. Morgantown, WV: Monongalia Schools.

Buggey, T. (2005). Video self-modeling applications with students with autism spectrum disorder in a small private school setting. Focus on Autism and Other Developmental Disabilities, 20(1), 52-63. Retrieved from WVU Electronic Journals database.

Conroy, M. A., Asmus, J. M., Ladwig, C. N., Sellers, J. A., \& Valcante, G. (2004). The effects of proximity on the classroom behaviors of students with autism in general education settings. Behavioral Disorders, 29(2), 119-129. Retrieved from WVU Electronic Journals database.

Delano, M. E. (2007). Video modeling interventions for individuals with autism. Remedial and Special Education, 28(1), 33-42. Retrieved from WVU Electronic Journals database.

Department of Health and Human Services, Centers for Disease Control and Prevention \& National Center on Birth Defects and Developmental Disabilities. (2007). Autism spectrum disorders fact sheet. Retrieved 12/13, 2007, from http://purl.access.gpo.gov/GPO/LPS71189.

Diagnostic and statistical manual of mental disorders (DSM-IV). (1994). Washington, D.C.: American Psychiatric Association.

Dyck, M. J., Piek, J. P., Hay, D. A., \& Hallmayer, J. F. (2007). The relationship between symptoms and abilities in autism. Journal of Developmental and Physical Disabilities, 19, 251-261.

Eikeseth, S., Smith, T., \& Eldevik, E. J. S. (2002). Intensive behavioral treatment at school for 4 to 7 year old children with autism. Behavior Modification, 26(1), 49-68. Retrieved from Sage Publications database.

Frederick, L. D., \& Hummel, J. H. (2004). Reviewing the outcomes and principles of effective instruction. In D. J. Moran, \& R. W. Malott (Eds.), Evidenced based educational methods (pp. 9-22). San Diego, CA: Elsevier Academic Press.

Heward, W. L. (2006). Emotional and behavioral disorders. In Exceptional children: An introduction to special education (pp. 218-259). Upper Saddle River, NJ: Pearson Education Incorporated. 
Levy, S., Kim, A., \& Olive, M. L. (2006). Interventions for young children with autism: A synthesis of the literature. Focus on Autism and Other Developmental Disabilities, 21(1), 55-62. Retrieved from WVU Electronic Journals database.

Mesibov, G. B., \& Shea, V. (1996). Full inclusion and students with autism. Journal of Autism and Developmental Disabilities, 26(3), 337-346. Retrieved from WVU Library Electronic Journals database.

National Institute of Neurological Disorders and Stroke. (2008). Autism fact sheet. Retrieved 9/8, 2008, from http://www.ninds.nih.gov/disorders/autism/detail_autism.html.

Ochs, E., Kremer-Sadlik, T., Solomon, O., \& Sirota, K. G. (2001). Inclusion as social practice: Views of children with autism. Social Development, 10(3), 399-419. Retrieved from WVU Electronic Journals database.

Odom, S. L., Brown, W. H., Frey, T., Karasu, N., Smith-Canter, L. L., \& Strain, P. S. (2003). Evidence based practices for young children with autism: Contributions for single subject design research. Focus on Autism and Other Developmental Disabilities, 18(3), 166-175. Retrieved from WVU Electronic Journals database.

Pierce, K., \& Schreibman, L. (1997). Multiple peer use of pivotal response training to increase social behaviors of classmates with autism: Results from trained and untrained peers. Journal of Applied Behavior Analysis, 30, 157-160. Retrieved from WVU Electronic Journals database.

Poe, S. G., Jaynes, M., \& Cobun, C. (2007). Klingberg neurodevelopmental center (Medical Report No. 1). Morgantown, WV: West Virginia University.

Polychronis, S. C., McDonnell, J., Johnson, J. W., Riesen, T., \& Jameson, M. (2004). A comparison of two trial distribution schedules in embedded instruction. Focus on Autism and Other Developmental Disabilities, 19(3), 140-151. Retrieved from WVU Electronic Journals database.

Sugai, G., Horner, R. H., Dunlap, G., Hieneman, M., Lewis, T. J., Nelson, M. C., et al. (2000). Applying positive behavior support and functional behavioral assessment in schools. Journal of Positive Behavioral Interventions, 2(3), 131-143. Retrieved from WVU Library Electronic Journals database.

Thiemann, K. S., \& Goldstein, H. (2001). Social stories, written texts, and video feedback: Effects on social communication of children with autism. Journal of Applied Behavior Analysis, 34, 425-446. Retrieved from WVU Electronic Journals database.

Tucci, V. (2006). Introductory CLM unit. Watsonville, CA: Tucci Learning Solutions.

Tucci, V., Hursh, D., \& Laitinen, R. (2004). The competent learner model: A merging of applied behavior analysis, direct instruction, and precision teaching. In D. J. Moran, \& R. W. Malott (Eds.), Evidence based educational methods (pp. 109-126). San Diego, CA: Elsevier Academic Press. 
Tucci, V., Hursh, D., Laitinen, R., \& Lambe, A. (2005). Competent learner model for individuals with Autism/PDD. Exceptionality, 13(1), 55-63.

Tucci, V., Shafer, E., \& Hursh, D. (2006). CLM course of study: Units 1-8. Watsonville, CA: Tucci Learning Solutions.

Warash, B., Curtis, R., Hursh, D., \& Tucci, V. (2008). Skinner meets Piaget on the Reggio playground: Practical synthesis of applied behavior analysis and developmentally appropriate practice orientations. Journal of Research in Childhood Education, 22(4), 441453.

Wolery, M., Barton, E. E., \& Hine, J. F. (2005). Evolution of applied behavior analysis in the treatment of individuals with autism. Exceptionality, 13(1), 11-23. Retrieved 4/1, 2008 from http://web.ebscohost.com/ehost/pdf?vid=3\&hid=103\&sid=f31782ea-42c9-401f-ac1a29d9840385ff\%40sessionmgr109.

Yell, M. L., Drasgow, E., \& Lowrey, K. A. (2005). No child left behind and students with autism spectrum disorders. Focus on Autism and Other Developmental Disabilities, 20(3), 130-139. Retrieved from WVU Library Electronic Journals database. 


\section{Appendix A}

Appropriate Participation—Engaged in the activity at hand without being disruptive.

- Following a teacher's instructions.

- Responding to statements or questions with answers that are relevant.

- Spontaneous conversation or statements related to the events/conversation at hand.

Inappropriate Participation—Disengaged and disruptive or engaged and disruptive.

- Yelling no.

- Crying.

- Responding to requests or questions with a "whiny" voice.

- Aggressive behavior.

- Taking items from peers or attempting to without their permission.

- Not following a teacher's instructions/questions/requests with this disturbing the group dynamic.

- Responding to questions/requests/conversations with replies not relevant to the situation.

Neutral Participation—Disengaged but not being disruptive.

- Not directly following teacher's instructions, but not causing the group dynamic to be disturbed (i.e. painting with white when instructed to paint with brown or building with blocks instead of participating in block center).

- Taking self-decided time outs.

- Not being engaged with the activity, but not disrupting.

- Not responding to a request or question, but not disrupting by this behavior (the teacher asks a question but the child doesn't answer and teacher moves on with no further redirection or requests). 


\section{Appendix B}

\begin{tabular}{|c|c|c|c|c|c|c|c|c|c|c|c|c|c|c|c|c|c|c|c|c|c|c|c|c|c|c|c|c|c|c|c|}
\hline Situation & \multicolumn{30}{|c|}{ (10) Second Intervals } & $\%$ \\
\hline & t & & & & + & + & t & t & + & + & + & + & + & + & + & t & + & + & + & + & t & t & + & + & $t$ & + & + & t & + & t & \\
\hline & - & - & - & - & - & - & - & - & - & - & - & - & - & - & - & - & - & - & - & - & - & - & - & - & - & - & - & - & - & & \\
\hline & 10 & 20 & 30 & 40 & 50 & 0 & 10 & 20 & 30 & 40 & 50 & 0 & 10 & 20 & 30 & 40 & 50 & 0 & 10 & 20 & 30 & 40 & 50 & 0 & 10 & 20 & 30 & 40 & 50 & 0 & \\
\hline & t & + & + & + & + & + & + & + & + & + & + & + & + & + & + & + & + & + & + & t & + & + & + & + & + & + & + & $t$ & + & + & \\
\hline & - & - & - & - & - & - & - & - & - & - & - & - & - & - & - & - & - & - & - & - & - & - & - & - & - & - & - & - & - & & \\
\hline & 10 & 20 & 30 & 40 & 50 & 0 & 10 & 20 & 30 & 40 & 50 & 0 & 10 & 20 & 30 & 40 & 50 & 0 & 10 & 20 & 30 & 40 & 50 & 0 & \begin{tabular}{|l|l}
10 \\
\end{tabular} & 20 & 30 & 40 & 50 & 0 & \\
\hline & + & + & $t$ & + & + & + & + & + & + & + & + & + & + & + & + & + & + & + & + & + & + & + & + & + & + & + & + & $t$ & + & + & \\
\hline & - & - & - & - & - & - & - & - & - & - & - & - & F & - & - & - & - & - & - & - & - & - & - & - & - & - & - & - & - & & \\
\hline & 10 & 20 & 30 & 40 & 50 & 0 & 10 & 20 & 30 & 40 & 50 & 0 & 10 & 20 & 30 & 40 & 50 & 0 & 10 & 20 & 30 & 40 & 50 & 0 & 10 & 20 & 30 & 40 & 50 & 0 & \\
\hline & + & + & $t$ & + & + & + & $t$ & + & $t$ & + & + & + & + & + & + & $t$ & + & + & + & + & + & + & $t$ & + & + & + & + & $t$ & + & + & \\
\hline & - & - & - & - & - & - & - & - & - & - & - & - & - & - & - & - & - & - & - & - & - & - & - & - & - & - & - & - & - & & \\
\hline & 10 & 20 & 30 & 40 & 50 & 0 & 10 & 20 & 30 & 40 & 50 & 0 & 10 & 20 & 30 & 40 & 50 & 0 & 10 & 20 & 30 & 40 & 50 & 0 & 10 & 20 & 30 & 40 & 50 & 0 & \\
\hline & + & + & + & + & + & + & + & + & $t$ & + & + & + & + & + & + & + & + & + & + & + & + & + & + & + & + & + & + & + & + & + & \\
\hline & - & - & - & - & - & - & - & - & - & - & - & - & - & - & - & - & - & - & - & - & - & - & - & - & - & - & - & - & - & & \\
\hline & 10 & 20 & 30 & 40 & 50 & 0 & 10 & 20 & 30 & 40 & 50 & 0 & 10 & 20 & 30 & 40 & 50 & 0 & 10 & 20 & 30 & 40 & 50 & 0 & 10 & 20 & 30 & 40 & 50 & 0 & \\
\hline & + & + & + & + & + & + & + & $t$ & + & + & + & + & + & + & + & + & + & t & + & + & + & + & + & + & + & + & + & + & + & + & \\
\hline & - & - & - & - & - & - & - & - & - & - & - & - & 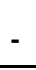 & - & - & - & - & - & - & - & & - & - & - & - & - & - & - & - & - & \\
\hline & + & + & $t$ & + & $t$ & + & $t$ & + & $t$ & + & $t$ & + & + & + & $t$ & $t$ & $t$ & + & + & + & + & + & + & + & $t$ & + & + & $t$ & + & + & \\
\hline & - & - & - & - & - & - & - & - & - & - & - & - & & - & - & - & - & - & - & - & - & - & - & - & - & - & - & - & - & - & \\
\hline & 10 & 20 & 30 & 40 & 50 & 0 & 10 & 20 & 30 & 40 & 50 & 0 & 10 & 20 & 30 & 40 & 50 & 0 & 10 & 20 & 30 & 40 & 50 & 0 & 10 & 20 & 30 & 40 & 50 & 0 & \\
\hline & + & + & + & + & + & + & + & + & + & + & + & + & t & + & + & + & + & + & + & + & + & + & + & + & + & + & + & + & + & + & \\
\hline & - & - & - & - & - & - & - & - & - & - & - & - & - & - & - & - & - & 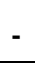 & & - & & - & - & - & & & - & & & - & \\
\hline
\end{tabular}




\section{Appendix C}

\begin{tabular}{|c|c|c|c|c|c|c|c|c|c|}
\hline & Trend & $\begin{array}{c}\text { Change in } \\
\text { Trend }\end{array}$ & Mean & $\begin{array}{c}\text { Change in } \\
\text { Mean }\end{array}$ & $\begin{array}{l}\text { Standard } \\
\text { Deviation }\end{array}$ & $\begin{array}{l}\text { Change in } \\
\text { Standard } \\
\text { Deviation }\end{array}$ & First Point & Final Point & $\begin{array}{c}\text { Level } \\
\text { Change }\end{array}$ \\
\hline Morning Circle Baseline & -0.30 & $\mathrm{~N} / \mathrm{A}$ & 30.94 & $\mathrm{~N} / \mathrm{A}$ & 12.27 & $\mathrm{~N} / \mathrm{A}$ & $N / A$ & 35.85 & $\mathrm{~N} / \mathrm{A}$ \\
\hline Intervention 1 & 0.63 & 0.93 & 41.55 & 10.61 & 12.07 & -0.20 & 47.37 & 40.24 & 11.52 \\
\hline Intervention 2 & 0.67 & 0.04 & 61.04 & 19.49 & 10.22 & -1.85 & 55.00 & $\mathrm{~N} / \mathrm{A}$ & 14.76 \\
\hline Rotating Center Phase 1 & 0.82 & $\mathrm{~N} / \mathrm{A}$ & 62.56 & $\mathrm{~N} / \mathrm{A}$ & 30.36 & $\mathrm{~N} / \mathrm{A}$ & $\mathrm{N} / \mathrm{A}$ & 0.00 & $\mathrm{~N} / \mathrm{A}$ \\
\hline Phase 2 & 0.61 & -0.21 & 88.22 & 25.66 & 14.14 & -16.22 & 98.33 & 85.00 & 98.33 \\
\hline Phase 3 & -0.49 & -1.10 & 82.67 & -5.55 & 17.14 & 3.00 & 63.33 & 60.87 & -21.67 \\
\hline Phase 4 & -0.52 & -0.03 & 85.81 & 3.14 & 19.30 & 2.16 & 96.67 & $\mathrm{~N} / \mathrm{A}$ & 35.80 \\
\hline Brown Table Phase 1 & 1.93 & $\mathrm{~N} / \mathrm{A}$ & 54.44 & $\mathrm{~N} / \mathrm{A}$ & 33.11 & $\mathrm{~N} / \mathrm{A}$ & $\mathrm{N} / \mathrm{A}$ & 87.50 & $\mathrm{~N} / \mathrm{A}$ \\
\hline Phase 2 & 0.34 & -1.59 & 76.86 & 22.42 & 13.65 & -19.46 & 78.33 & 97.96 & -9.17 \\
\hline Phase 3 & 2.55 & 2.21 & 85.24 & 8.38 & 9.97 & -3.68 & 64.71 & 96.67 & -33.25 \\
\hline Phase 4 & -1.00 & -3.55 & 85.28 & 0.04 & 23.50 & 13.53 & 91.67 & $\mathrm{~N} / \mathrm{A}$ & -5.00 \\
\hline & & & & & & & & & 21.24 \\
\hline Yellow Table Phase 1 & -0.74 & $\mathrm{~N} / \mathrm{A}$ & 57.94 & $\mathrm{~N} / \mathrm{A}$ & 21.24 & $\mathrm{~N} / \mathrm{A}$ & $\mathrm{N} / \mathrm{A}$ & 29.82 & $\mathrm{~N} / \mathrm{A}$ \\
\hline Phase 2 & -0.89 & -0.15 & 71.58 & 13.64 & 17.94 & -3.30 & 76.67 & 61.11 & 46.85 \\
\hline Phase 3 & -0.74 & 0.15 & 76.24 & 4.66 & 10.95 & -6.99 & 86.67 & 80.00 & 25.56 \\
\hline Phase 4 & 0.95 & 1.69 & 74.75 & -1.49 & 11.74 & 0.79 & 46.67 & $\mathrm{~N} / \mathrm{A}$ & -33.33 \\
\hline Afternoon Circle Baseline & -0.86 & $\mathrm{~N} / \mathrm{A}$ & 33.23 & $\mathrm{~N} / \mathrm{A}$ & 12.58 & $\mathrm{~N} / \mathrm{A}$ & $\mathrm{N} / \mathrm{A}$ & 26.67 & $\mathrm{~N} / \mathrm{A}$ \\
\hline Intervention 1 & 0.58 & 1.44 & 54.29 & 21.06 & 8.68 & -3.90 & 46.48 & $\mathrm{~N} / \mathrm{A}$ & 19.81 \\
\hline Afternoon Center Phase 1 & 2.90 & $\mathrm{~N} / \mathrm{A}$ & 61.11 & $\mathrm{~N} / \mathrm{A}$ & 31.12 & $\mathrm{~N} / \mathrm{A}$ & $\mathrm{N} / \mathrm{A}$ & 51.67 & $\mathrm{~N} / \mathrm{A}$ \\
\hline Phase 2 & -0.49 & -3.39 & 92.46 & 31.35 & 7.11 & -24.01 & 96.36 & 87.27 & 44.69 \\
\hline Phase 3 & 4.71 & 5.20 & 78.85 & -13.61 & 22.13 & 15.02 & 66.67 & 93.33 & -20.60 \\
\hline Phase 4 & 0.73 & -3.98 & 92.39 & 13.54 & 5.29 & -16.84 & 90.00 & $\mathrm{~N} / \mathrm{A}$ & -3.33 \\
\hline Art Phase 1 & -2.20 & $\mathrm{~N} / \mathrm{A}$ & 45.70 & $\mathrm{~N} / \mathrm{A}$ & 23.95 & $\mathrm{~N} / \mathrm{A}$ & $\mathrm{N} / \mathrm{A}$ & 20.55 & $\mathrm{~N} / \mathrm{A}$ \\
\hline Phase 2 & -0.99 & 1.21 & 72.85 & 27.15 & 16.75 & -7.20 & 66.67 & 81.03 & 46.12 \\
\hline Phase 3 & 7.63 & 8.62 & 69.07 & -3.78 & 19.07 & 2.32 & 50.00 & 88.14 & -31.03 \\
\hline Phase 4 & 0.53 & -7.10 & 70.14 & 1.07 & 11.68 & -7.39 & 50.91 & $\mathrm{~N} / \mathrm{A}$ & -37.23 \\
\hline Library Phase 1 & 1.81 & $\mathrm{~N} / \mathrm{A}$ & 60.84 & $\mathrm{~N} / \mathrm{A}$ & 10.84 & $\mathrm{~N} / \mathrm{A}$ & $\mathrm{N} / \mathrm{A}$ & 71.67 & $\mathrm{~N} / \mathrm{A}$ \\
\hline Phase 2 & -0.62 & -2.43 & 67.81 & 6.97 & 7.35 & -3.49 & 65.52 & 63.33 & -6.15 \\
\hline Phase 3 & -9.17 & -8.55 & 55.83 & -11.98 & 9.17 & 1.82 & 65.00 & 46.66 & 1.67 \\
\hline Phase 4 & -4.55 & 4.62 & 59.09 & 3.26 & 7.42 & -1.75 & 68.18 & $\mathrm{~N} / \mathrm{A}$ & 21.52 \\
\hline Music Phase 1 & -1.57 & $\mathrm{~N} / \mathrm{A}$ & 20.96 & $\mathrm{~N} / \mathrm{A}$ & 12.74 & $\mathrm{~N} / \mathrm{A}$ & $\mathrm{N} / \mathrm{A}$ & 11.67 & $\mathrm{~N} / \mathrm{A}$ \\
\hline Phase 2 & 0.49 & 2.06 & 61.74 & 40.78 & 18.80 & 6.06 & 54.35 & 72.41 & 42.68 \\
\hline Phase 3 & 2.59 & 2.10 & 44.42 & -17.32 & 7.90 & -10.90 & 35.00 & 50.91 & -37.41 \\
\hline Phase 4 & 3.77 & 1.18 & 60.28 & 15.86 & 21.22 & 13.32 & 35.85 & $\mathrm{~N} / \mathrm{A}$ & -15.06 \\
\hline
\end{tabular}

